\title{
Second-order torsional warping theory considering the secondary torsion-moment deformation-effect
}

\author{
Mehdi Aminbaghai ${ }^{1 *}$, Justin Murin ${ }^{2}$, Giuseppe Balduzzi ${ }^{1}$, Juraj Hrabovsky ${ }^{2}$, \\ Georg Hochreiner ${ }^{1}$, Herbert A. Mang ${ }^{1,3}$ \\ ${ }^{1}$ Vienna University of Technology, Institute for Mechanics of Materials and Structures, \\ Karlsplatz 13, A-1040 Vienna, Austria \\ mehdi.aminbaghai@tuwien.ac.at, giuseppe.balduzzi@tuwien.ac.at, \\ georg.hochreiner@tuwien.ac.at, herbert.mang@,tuwien.ac.at \\ ${ }^{2}$ Department of Applied Mechanics and Mechatronics, IAMM FEI STU in \\ Bratislava, Ilkovičova 3, 81219 Bratislava, Slovakia \\ justin.murin@stuba.sk,juraj.hrabovsky@stuba.sk \\ ${ }^{3}$ National RPGE Chair Professor, Tongji University, Siping Road 1239, Shanghai, China, \\ herbert.mang@tuewien.ac.at \\ This document is the accepted version of a work that was published in \\ Engineering Structures. To access the final edited and published work \\ see, https://doi.org/10.1016/j.engstruct.2017.06.023. This manuscript \\ version is made available under the CC-BY-NC-ND 4.0 license \\ https://creativecommons.org/licenses/by-nc-nd/4.0/.
}

Keywords: Second-order torsional warping theory, Warping torsional eigenvibrations, Secondary torsion-moment deformation-effect, Transfer matrix, Element matrices in the framework of the Finite Element Method, Beams with thinwalled closed and open cross-sections

\begin{abstract}
In this paper, the influence of the variable axial force and of the Secondary TorsionMoment Deformation-Effect (STMDE) on the deformations of beams due to torsional warping is investigated. The investigation is based on the second-order torsional warping theory of doubly symmetric beams with thin-walled open or closed cross-sections. The effect of the axial force on the torsional stiffness of thinwalled beams is considered according to the second-order torsional warping theory. The solutions of the underlying differential equations are used for setting up the relations, needed for application of the transfer matrix method. They are derived, considering both static and dynamic action. This enables stablishing the local

${ }^{*}$ Corresponding author: Mehdi Aminbaghai, Vienna University of Technology, Institute for Mechanics of Materials and Structures, Karlsplatz 13, A-1040 Vienna, Austria, mehdi.aminbaghai@tuwien.ac.at.
\end{abstract}


element matrix of the twisted beam in the framework of the Finite Element Method (FEM). The numerical investigation comprises static and modal analyses of thinwalled beams with I cross-sections and rectangular hollow cross-sections. The results are compared with results obtained by the FEM, using solid and beam elements available in standard software.

\section{Introduction}

The effect of non-uniform torsion must be considered in structural analysis of thinwalled beams with open as well as closed cross-sections. The maximum axial stress caused by the bimoment occurs at the points of action of external torques (except for free ends of beams) and at cross-sections of restrained warping (for example clamped cross-sections). A broad comprehensive overview of the literature dealing with the issue of non-uniform torsion can be found, for example, in [1] and [2]. Recent research results have shown that for non-uniform torsion of beams with closed cross-sections the influence of the Secondary Torsion-Moment Deformation-Effect (STMDE) is particularly significant.

Beam structures are frequently exposed to dynamic loads. Commercial FEM codes enable modal and transient analysis by 3D finite beam elements without and with consideration of warping [3]-[5]. For torsion, very often an improved Saint-Venant theory is used and special mass matrices are considered. In general, the bicurvature is chosen as an additional warping degree of freedom, and the STMDE is not considered (Ref. [5] is an exception). The beam element in [4] can be used with a lumped or a consistent mass matrix. The consistent mass matrix includes warping effects, but does not include the effect of shear deformations. For standard beam elements, the consistent mass matrix is based on reference [6], with the exception of additional terms arising from the warping constant $I_{\omega}$. For the warping element, lumped masses for the warping degree of freedom (bicurvature) are defined in [7]. As stated in [4], for solid and closed thin-walled sections, standard finite beam elements can be used without significant error. However, for open thin-walled sections, warping finite beam elements should be used. In [5], however, the warping finite beam element is recommended only for use for open thin-walled section beams. In [8], a boundary element method is developed for the non-uniform torsional vibration problem of doubly symmetric constant cross-sections, accounting for non-uniform warping and secondary torsional shear deformationeffects. Dynamic analysis of 3D beam elements, restrained at their edges and subjected to arbitrarily distributed dynamic loading is described in [9]. In [10], an elastic non-uniform torsion analysis of simply or multiply connected cylindrical bars with arbitrary cross-sections accounts for the effect of geometric non-linearity in the framework of the boundary-element method. In [11], the effect of rotary and warping inertia is considered. Nonlinear torsional vibrations of thin-walled beams, exhibiting primary and secondary warping, are investigated in [12]. A solution for the vibrations of Timoshenko beams by the isogeometric approach is presented in [13]. Warping effects, however, are not considered. In [14], geometrically nonlinear free and forced vibrations of beams with non-symmetrical cross-sections are 
investigated by the Saint-Venant theory of torsion. Axial-torsional vibrations of rotating pretwisted thin-walled composite box beams, exhibiting primary and secondary warping, are investigated in [15]. A formulation of a 3D beam element for computation of transversal and warping eigenmodes is presented in [16].

In [17], a new 3D finite element for geometrically nonlinear analysis of beams, made of Functionally Graded Material (FGM) with transversally varying material properties, is presented. The warping displacements are accurately predicted.

In [1], the influence of torsional warping of open and closed cross-sections of twisted beams, made of materials with constant material properties, on their eigenvibrations is investigated, considering the secondary deformations due to the angle of twist. Since the bicurvature cannot be used in the constraint equations, see. e.g. [4], it was logical to consider the part of the first derivative of the angle of twist, caused by the bimoment, as the warping degree of freedom [18] also for modal analysis. The results from modal analysis, concerning non-uniform and uniform torsion of beams with open cross-sections, have shown large differences of the eigenfrequencies. This has corroborated the well-known fact that warping must be taken into account also for modal analysis of beams with open cross-sections, subjected to torsion. It was also shown that the STMDE does not play a significant role in torsion of beams with open cross-sections. On the other hand, the torsional eigenfrequencies, obtained in case of consideration of STMDE, are very close to the ones obtained by 3D solid finite elements. In contrast to open cross-sections, the influence of warping (with or without STMDE) on the non-uniform torsional eigenfrequencies of beams with rectangular hollow cross-sections is not significant. The best agreement of results obtained by solid finite elements and by the method proposed in [1] (both for the Saint-Venant and the warping beam solutions) is obviously achieved for the first torsional eigenfrequency. For the higher modes, the difference between corresponding results increases especially for short beams. Some higher torsional eigenmodes, calculated by means of solid finite elements, contain deformations of the side walls of the beams. This effect cannot be considered in a straightforward manner by finite beam elements with restrained and unrestrained warping. As shown in [19], all eigenfrequencies calculated by solid finite elements agree very well with results obtained by experimental measurements.

Other very recent aspects in the area of numerical solutions of non-uniform torsion are treated in [20]-[24]. Finally, in [2], a boundary element solution is developed for dynamic analysis, considering warping of beams with arbitrary cross-sections, including shear lag effects due to both flexure and torsion. High accuracy of the results in comparison to the ones obtained by solid finite element solution is obtained. However, in the solid model, the distortion effect of the cross-section was restrained.

A common feature of the above cited articles is disregard of the effect of the variable axial force on torsional warping.

In this paper, the work reported in [1] is extended to uniform and non-uniform torsional analysis of beams with a variable axial force. In Chapter 2, the differential equations of beams with such an axial force are formulated for Saint-Venant and non-uniform torsional deformations, including inertial line moments. In non- 
uniform torsion, the part of the bicurvature, caused by the bimoment, is taken into account as the warping degree of freedom, and the STMDE is also considered. A general semi-analytical solution of the differential equation is presented in Chapter 3 , the transfer matrix relation is established in Chapter 4, from which the finite element equations for beam elements with two nodes are derived in Chapter 5. Omitting the external load, the FEM equation for the torsional natural free vibrations is obtained. The numerical investigation in Chapter 6 deals with torsional modal and elastostatic analysis of thin-walled beams with I cross-sections and rectangular hollow cross-sections. The obtained results are compared with the ones from commercial FEM codes. The effect of the axial force is evaluated. A final assessment of the proposed method is contained in the conclusions. Some of the mathematical details are explained in the Appendix.

The main novelties of the present paper are:

- (1) consideration of a variable axial force and of the STMDE in the differential equation for non-uniform torsion of thin-walled beams with open and closed crosssections according to the theory of second-order torsional warping;

- (2) formulation of the equations needed for the transfer matrix method and the FEM for elastostatic and modal analysis of non-uniformly twisted beams according to this theory.

\section{Differential equation of the torsional deformations of beams with variable axial forces}

According to the theory of second-order torsional warping, the axial forces affect the torsional stiffness $G I_{T}$, where $G$ is the shear modulus and $I_{T}$ is the torsion constant. Basically, compression results in a decrease and traction in an increase of the torsional stiffness $G I_{T}$ of the beam. This situation may be considered by an additional stiffness $N i_{p}^{2}$ (e.g. [25]) for doubly symmetric cross-sections, where $N$ is the known axial force, acting at the center point of the cross-section, and $i_{p}=\sqrt{I_{P} / A}$ denotes the radius of gyration and $I_{P}$ is the polar moment of area. In case of a variable axial force $N^{I I}(x)=N(x)$, the corresponding variable torsional stiffness is obtained as $G I_{T}^{*}(x)=G I_{T}+N^{I I}(x) i_{p}^{2}$, where the term $N^{I I}(x) i_{p}^{2}$ denotes the so-called geometric stiffness. Representing a load, the axial force $N(x)$ appears in the respective term of the differential equation for the displacement in the longitudinal direction. The variable axial force $N^{I I}(x)$ appears in the homogeneous part of the differential equation for the angle of twist. The variation of the known axial force $N^{I I}(x)$ accounts for the stiffening or softening of the torsional stiffness in the framework of the second-order torsional warping theory. For doubly symmetric cross-sections, the torsional deformations are decoupled from the bending deformations and the longitudinal deformations. For this case, the differential equation for the angle of twist will be established in this Chapter. 


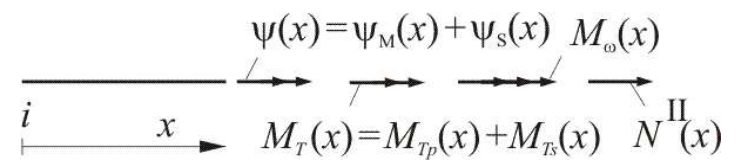

Fig. 1: Second-order torsional warping theory: axial force, torsional moments and angles of twist.

Fig. 1 refers to the second-order torsional warping theory. It shows the axial force $N^{I I}(x)$, the torsional moment $M_{T}(x)$ as the sum of the primary torsional moment, $M_{T p}(x)$, and the secondary torsional moment, $M_{T S}(x)$, and the bimoment $M_{\omega}(x)$ . Fig. 1 also shows the angle of twist, $\psi(x)$, corresponding to $M_{T p}(x)$. It represents the sum of the angle of twist, resulting from the primary deformation, $\psi_{M}^{\prime}(x)$, and the secondary deformation $\psi_{S}^{\prime}(x)$.

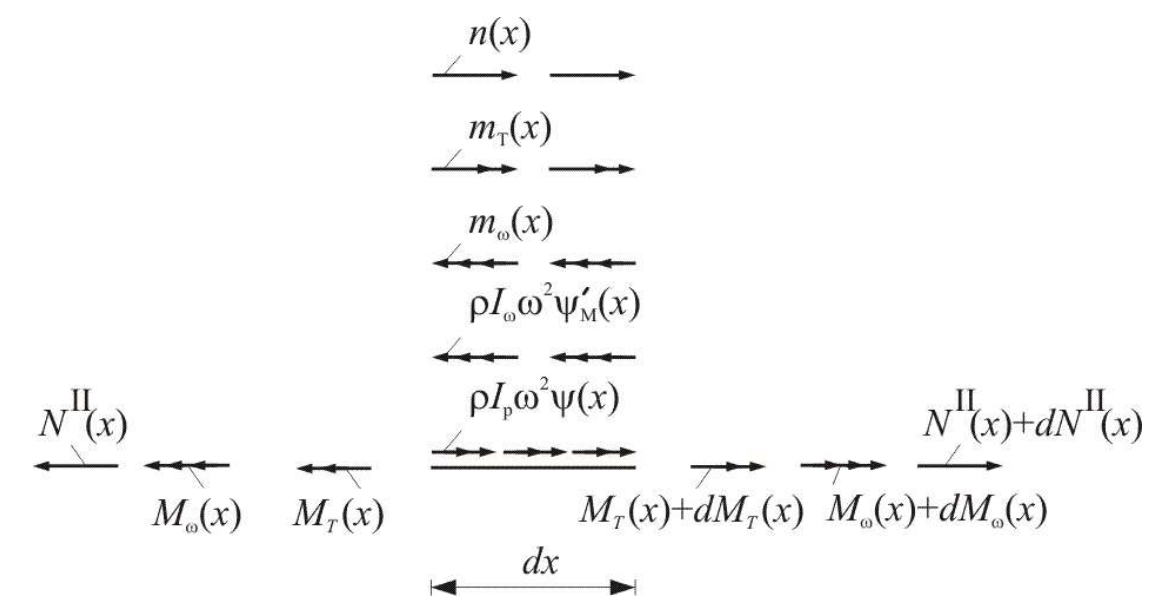

Fig. 2: Second-order torsional warping theory: static load and moments and static equivalent of the respective dynamic load, acting on an infinitesimal beam element.

Fig. 2 illustrates an infinitesimal element of the beam. $I_{\omega}$ stands for the warping constant and $\omega$ indicates the circular natural frequency.

According to modal analysis, the angle of twist, $\psi(x, t)=\psi(x) \cos (\omega t)$, depends on both the location $x$ and the time $t$. The acceleration is defined as the second derivative of the angle of twist $\psi(x, t)$ with respect to the $t$, i.e. $\ddot{\psi}(x, t)=-\omega^{2} \psi(x) \cos (\omega t)$. The maximum value of the displacement, $\max \psi(x, t)$, is obtained for $\cos (\omega t) \equiv 1$. The equivalent static torsional line moment is defined as $-\rho I_{p} \ddot{\psi}(x, t)=\rho I_{p} \omega^{2} \psi(x) \underbrace{\cos (\omega t)}_{1}=\rho I_{p} \omega^{2} \psi(x)$.

The equivalent static line bimoment is obtained as $-\rho I_{\omega} \ddot{\psi}_{M}^{\prime}(x, t)=\rho I_{\omega} \omega^{2} \psi_{M}^{\prime}(x) \underbrace{\cos (\omega t)}_{1}=\rho I_{\omega} \omega^{2} \psi_{M}^{\prime}(x)$. 
These loads represent the static equivalent of the respective dynamic action at the instant of time, corresponding to the maximum value of the displacement. In this way, the variable $t$ is eliminated.

The static loads are the warping moment per unit length, $m_{\omega}$, the torsional moment per unit length, $m_{T}$ and the axial force per unit length, $n$.

The polynomial representation of $m_{T}$ is given as:

$$
m_{T}(x)=\sum_{k=0}^{p_{m T}} m_{T, k} x^{k}=m_{T, 0} x^{0}+m_{T, 1} x^{1}+m_{T, 2} x^{2}+\ldots+m_{T, p_{m T}} x^{p_{m T}},
$$

where $m_{T, k}\left(m_{T, 0}, \ldots, m_{T, P_{m T}}\right)$ are constants and $x$ is the axial coordinate. $p_{m T}$ is the maximum degree of this polynomial function, and the index $T$ stands for "torsional".

The polynomial representation of the torsional bimoment per unit length is given as:

$$
m_{\omega}(x)=\sum_{k=0}^{p_{m \omega}} m_{\omega, k} x^{k}=m_{\omega, 0} x^{0}+m_{\omega, 1} x^{1}+m_{\omega, 2} x^{2}+\ldots+m_{\omega, p_{m \omega}} x^{p_{m \omega}}
$$

where $m_{\omega, k}\left(m_{\omega, 0}, \ldots, m_{\omega, P_{m \omega}}\right)$ are constants. $p_{m \omega}$ is the maximum degree of the polynomial function, and the index $\omega$ refers to the torsional bimoment.

In the following, the equilibrium equations will be formulated according to [1]:

$$
\begin{gathered}
M_{T}^{\prime}(x)=-\rho I_{p} \omega^{2} \psi(x)-m_{T}(x), \\
M_{\omega}^{\prime}(x)=M_{T}(x)-M_{T p}(x)+\rho I_{\omega} \omega^{2} \psi_{M}^{\prime}(x)+m_{\omega}(x), \\
M_{\omega}^{\prime}(x)=M_{T S}(x)+\rho I_{\omega} \omega^{2} \psi_{M}^{\prime}(x)+m_{\omega}(x),
\end{gathered}
$$

where

$$
M_{T}(x)=M_{T p}(x)+M_{T s}(x) .
$$

According to [26],

$$
\psi_{M}^{\prime \prime}(x)=-\frac{M_{\omega}(x)}{E I_{\omega}}
$$

and

$$
\psi^{\prime}(x)=\psi_{M}^{\prime}(x)+\psi_{S}^{\prime}(x)
$$

with 


$$
\psi^{\prime}(x)=\frac{M_{T p}(x)}{G I_{T}^{*}(x)}=\frac{M_{T p}(x)}{G I_{T}+N^{I I}(x) i_{p}^{2}}
$$

and

$$
\psi_{S}^{\prime}(x)=\frac{M_{T S}(x)}{G I_{T S}},
$$

where $I_{T S}$ denotes the secondary torsion constant.

Differentiation of equation (8) with respect to $x$ and consideration of the equations (7) and (10) gives

$$
\psi^{\prime \prime}(x)=\psi_{M}^{\prime \prime}(x)+\frac{M_{T S}^{\prime}(x)}{G I_{T S}}=-\frac{M_{\omega}(x)}{E I_{\omega}}+\frac{M_{T S}^{\prime}(x)}{G I_{T S}} .
$$

Making use of the equations (3) and (7) and of the derivative of equation (6) in equation (11) yields

$$
\begin{aligned}
& \psi^{\prime \prime}(x)=\psi_{M}^{\prime \prime}(x)+\frac{M_{T s}^{\prime}(x)}{G I_{T S}}=-\frac{M_{\omega}(x)}{E I_{\omega}}+\frac{M_{T}^{\prime}(x)-M_{T p}^{\prime}(x)}{G I_{T s}} \\
& =-\frac{M_{\omega}(x)}{E I_{\omega}}+\frac{-\rho I_{p} \omega^{2} \psi(x)-m_{T}(x)-M_{T p}^{\prime}(x)}{G I_{T s}} \\
& =-\frac{M_{\omega}(x)}{E I_{\omega}}+\frac{-\rho I_{p} \omega^{2} \psi(x)-m_{T}(x)-G I_{T}^{*} \psi^{\prime \prime}(x)-G I_{T}^{* \prime} \psi^{\prime}(x)}{G I_{T s}} .
\end{aligned}
$$

Multiplication of equation (12) by $E I_{\omega}$ results in

$$
\begin{aligned}
& E I_{\omega} \psi^{\prime \prime}(x)+M_{\omega}(x)+\frac{E I_{\omega}}{G I_{T S}}\left(\rho I_{p} \omega^{2} \psi(x)+m_{T}(x)+G I_{T}^{*} \psi^{\prime \prime}(x)+G I_{T}^{* \prime} \psi^{\prime}(x)\right)= \\
& =E I_{\omega}\left(1+\frac{G I_{T}^{*}}{G I_{T s}}\right) \psi^{\prime \prime}(x)+M_{\omega}(x)+\frac{E I_{\omega}}{G I_{T S}}\left(\rho I_{p} \omega^{2} \psi(x)+m_{T}(x)+G I_{T}^{* \prime} \psi^{\prime}(x)\right)=0 .
\end{aligned}
$$

Differentiation of equation (13) with respect to $x$ and substitution of equation (6) into the so-obtained relation yields

$$
\begin{aligned}
& E I_{\omega}\left(1+\frac{G I_{T}^{*}}{G I_{T s}}\right) \psi^{\prime \prime \prime}(x)+2 \frac{E I_{\omega}}{G I_{T s}} G I_{T}^{* \prime} \psi^{\prime \prime}(x)+\frac{E I_{\omega}}{G I_{T s}}\left(G I_{T}^{* \prime \prime}+\rho I_{p} \omega^{2}\right) \psi^{\prime}(x) \\
& +M_{T}(x)-M_{T p}(x)+\rho I_{\omega} \omega^{2} \psi_{M}^{\prime}(x)+m_{\omega}(x)+\frac{E I_{\omega}}{G I_{T s}} m_{T}^{\prime}(x)=0 .
\end{aligned}
$$

Consideration of the equations (8), (9), and (10) in equation (14) yields

$$
\begin{aligned}
& E I_{\omega}\left(1+\frac{G I_{T}^{*}}{G I_{T s}}\right) \psi^{\prime \prime \prime}(x)+2 \frac{E I_{\omega}}{G I_{T S}} G I_{T}^{* \prime} \psi^{\prime \prime}(x)+\frac{E I_{\omega}}{G I_{T S}}\left(G I_{T}^{* \prime \prime}+\rho I_{p} \omega^{2}\right) \psi^{\prime}(x) \\
& +M_{T}(x)-G I_{T}^{*} \psi^{\prime}(x)+\rho I_{\omega} \omega^{2}\left(\psi^{\prime}(x)-\frac{M_{T S}(x)}{G I_{T S}}\right)+m_{\omega}(x)+\frac{E I_{\omega}}{G I_{T S}} m_{T}^{\prime}(x)=0 .
\end{aligned}
$$


Differentiation of equation (15) with respect to $x$ and consideration of equation (6) results in

$$
\begin{aligned}
& E I_{\omega}\left(1+\frac{G I_{T}^{*}}{G I_{T s}}\right) \psi^{\prime \prime \prime \prime}(x)+3 \frac{E I_{\omega}}{G I_{T s}} G I_{T}^{* \prime} \psi^{\prime \prime \prime}(x) \\
& +\left(\frac{E I_{\omega}}{G I_{T s}} \rho I_{p} \omega^{2}+3 \frac{E I_{\omega}}{G I_{T s}} G I_{T}^{* \prime \prime}+\rho I_{\omega} \omega^{2}-G I_{T}^{*}\right) \psi^{\prime \prime}(x) \\
& +\left(\frac{E I_{\omega}}{G I_{T s}} G I_{T}^{* \prime \prime \prime}-G I_{T}^{* \prime}\right) \psi^{\prime}(x)+M_{T}^{\prime}(x) \\
& -\frac{\rho I_{\omega} \omega^{2}}{G I_{T s}}\left(M_{T}^{\prime}(x)-M_{T p}^{\prime}(x)\right)+m_{\omega}^{\prime}(x)+\frac{E I_{\omega}}{G I_{T s}} m_{T}^{\prime \prime}(x)=0 .
\end{aligned}
$$

Substitution of equation (3) and of the derivative of equation (9) into equation (16) gives

$$
\begin{aligned}
& E I_{\omega}\left(1+\frac{G I_{T}^{*}}{G I_{T s}}\right) \psi^{\prime \prime \prime \prime}(x)+3 \frac{E I_{\omega}}{G I_{T s}} G I_{T}^{* \prime} \psi^{\prime \prime \prime}(x) \\
& +\left(\frac{E I_{\omega}}{G I_{T s}} \rho I_{p} \omega^{2}+3 \frac{E I_{\omega}}{G I_{T s}} G I_{T}^{* \prime \prime}+\rho I_{\omega} \omega^{2}+G I_{T}^{*}\left(\frac{\rho I_{\omega} \omega^{2}}{G I_{T s}}-1\right)\right) \psi^{\prime \prime}(x) \\
& +\left(\frac{E I_{\omega}}{G I_{T s}} G I_{T}^{* \prime \prime \prime}+G I_{T}^{* \prime}\left(\frac{\rho I_{\omega} \omega^{2}}{G I_{T s}}-1\right)\right) \psi^{\prime}(x)+\rho I_{p} \omega^{2}\left(\frac{\rho I_{\omega} \omega^{2}}{G I_{T s}}-1\right) \psi(x) \\
& =-\left(\frac{\rho I_{\omega} \omega^{2}}{G I_{T s}}-1\right) m_{T}(x)-\frac{E I_{\omega}}{G I_{T s}} m_{T}^{\prime \prime}(x)-m_{\omega}^{\prime}(x) .
\end{aligned}
$$

Equation (17) is a linear differential equation of fourth order for the angle of twist according to the second-order torsional warping theory.

The above linear differential equation of 4th order with variable coefficients can formally be written as

$$
\begin{aligned}
& \eta_{4}(x) \psi^{\prime \prime \prime}(x)+\eta_{3}(x) \psi^{\prime \prime \prime}(x)+\eta_{2}(x) \psi^{\prime \prime}(x)+\eta_{1}(x) \psi^{\prime}(x)+\eta_{0}(x) \psi(x) \\
& =\eta_{L}(x)=\sum_{s=0}^{\max s} \eta_{L, s} x^{s}
\end{aligned}
$$

where

$$
\begin{gathered}
\eta_{0}(x)=\sum_{s=0}^{\max \eta_{0}} \eta_{0, s} x^{s}=\rho I_{p} \omega^{2}\left(\frac{\rho I_{\omega} \omega^{2}}{G I_{T s}}-1\right), \\
\eta_{1}(x)=\sum_{s=0}^{\max \eta_{1}} \eta_{1, s} x^{s}=\left(\frac{E I_{\omega}}{G I_{T s}} G I_{T}^{* \prime \prime \prime}+G I_{T}^{* \prime}\left(\frac{\rho I_{\omega} \omega^{2}}{G I_{T s}}-1\right)\right) \\
\eta_{2}(x)=\sum_{s=0}^{\max \eta_{2}} \eta_{2, s} x^{s}=\left(\frac{E I_{\omega}}{G I_{T s}} \rho I_{p} \omega^{2}+3 \frac{E I_{\omega}}{G I_{T S}} G I_{T}^{* \prime \prime}+\rho I_{\omega} \omega^{2}+G I_{T}^{*}\left(\frac{\rho I_{\omega} \omega^{2}}{G I_{T s}}-1\right)\right),
\end{gathered}
$$




$$
\begin{gathered}
\eta_{3}(x)=\sum_{s=0}^{\max \eta_{3}} \eta_{3, s} x^{s}=3 \frac{E I_{\omega}}{G I_{T s}} G I_{T}^{* \prime} \\
\eta_{4}(x)=\sum_{s=0}^{\max \eta_{4}} \eta_{4, s} x^{s}=E I_{\omega}\left(1+\frac{G I_{T}^{*}}{G I_{T s}}\right),
\end{gathered}
$$

and

$$
\eta_{L}(x)=\sum_{s=0}^{\max s} \eta_{L, s} x^{s}=-\left(\frac{\rho I_{\omega} \omega^{2}}{G I_{T s}}-1\right) m_{T}(x)-\frac{E I_{\omega}}{G I_{T s}} m_{T}^{\prime \prime}(x)-m_{\omega}^{\prime}(x) .
$$

In equation (24), $\eta_{L, s}\left(\eta_{L, 0}, \ldots, \eta_{L, \max s}\right)$ are known constant coefficients.

In case of a constant torsional stiffness $\left(N^{I I}(x)=0 \Rightarrow G I_{T}^{*}=G I_{T}\right)$, equation (17) belongs to the category of non-uniform torsion (first-order torsional warping theory, e.g. [1]). Equation (17) represents the mathematical formulation of the second-order torsional warping theory without consideration of the secondary torsion-moment deformation-effect (e.g. [25]).

Neglecting this effect by setting $G I_{T S}=\infty$, and setting $I_{\omega}=0$, equation (17) degenerates to the respective relation in the framework of Saint-Venant torsion, including the effect of the variable axial force, which results in the geometric stiffness. Thus,

$$
G I_{T}^{*} \psi^{\prime \prime}(x)+G I_{T}^{* \prime} \psi^{\prime}(x)+\rho I_{p} \omega^{2} \psi(x)=-m_{T}(x) .
$$

\section{Semi-analytical solution of the differential equation of fourth order for the angle of twist}

The general semi-analytical solution of the differential equation (18) can be written as follows [27]:

$$
\psi(x)=b_{0}(x) \psi_{i}+b_{1}(x) \psi_{i}^{\prime}+b_{2}(x) \psi_{i}^{\prime \prime}+b_{3}(x) \psi_{i}^{\prime \prime \prime}+\sum_{s=0}^{\max s} \eta_{L, s} b_{s+4}(x),
$$

where $b_{0}(x), b_{1}(x), b_{2}(x), b_{3}(x), \ldots, b_{s+4}(x), s \in<0$, $\max s>$, denote the transfer functions [27] and $\psi_{i}, \psi_{i}^{\prime}, \psi_{i}^{\prime \prime}, \psi_{i}^{\prime \prime \prime}$ represent the integration constants, referring to the starting point $i$.

Equation (26) and its first three derivatives with respect to $x$ are combined to the following matrix equation: 


$$
\left|\begin{array}{c}
\psi(x) \\
\psi^{\prime}(x) \\
\psi^{\prime \prime}(x) \\
\psi^{\prime \prime \prime}(x)
\end{array}\right|=\left|\begin{array}{llll}
b_{0}(x) & b_{1}(x) & b_{2}(x) & b_{3}(x) \\
b_{0}^{\prime}(x) & b_{1}^{\prime}(x) & b_{2}^{\prime}(x) & b_{3}^{\prime}(x) \\
b_{0}^{\prime \prime}(x) & b_{1}^{\prime \prime}(x) & b_{2}^{\prime \prime}(x) & b_{3}^{\prime \prime}(x) \\
b_{0}^{\prime \prime \prime}(x) & b_{1}^{\prime \prime \prime}(x) & b_{2}^{\prime \prime \prime}(x) & b_{3}^{\prime \prime \prime}(x)
\end{array}\right| \cdot\left|\begin{array}{c}
\psi_{i} \\
\psi_{i}^{\prime} \\
\psi_{i}^{\prime \prime} \\
\psi_{i}^{\prime \prime \prime}
\end{array}\right|+\mid \begin{aligned}
& \mid \begin{array}{l}
\sum_{s=0}^{\max s} \eta_{L s} b_{s+4}(x) \\
\sum_{s=0}^{\max s} \eta_{L s} b_{s+4}^{\prime}(x) \\
\sum_{s=0}^{\max s} \eta_{L s} b_{s+4}^{\prime \prime}(x) \\
\sum_{s=0}^{\max s} \eta_{L s} b_{s+4}^{\prime \prime \prime}(x)
\end{array} \\
& \psi^{L}
\end{aligned} .
$$

$\psi^{L}(x)$, which represents the load vector, is obtained from the particular solution of the differential equation (18).

The system of equations (27) can be rewritten as follows:

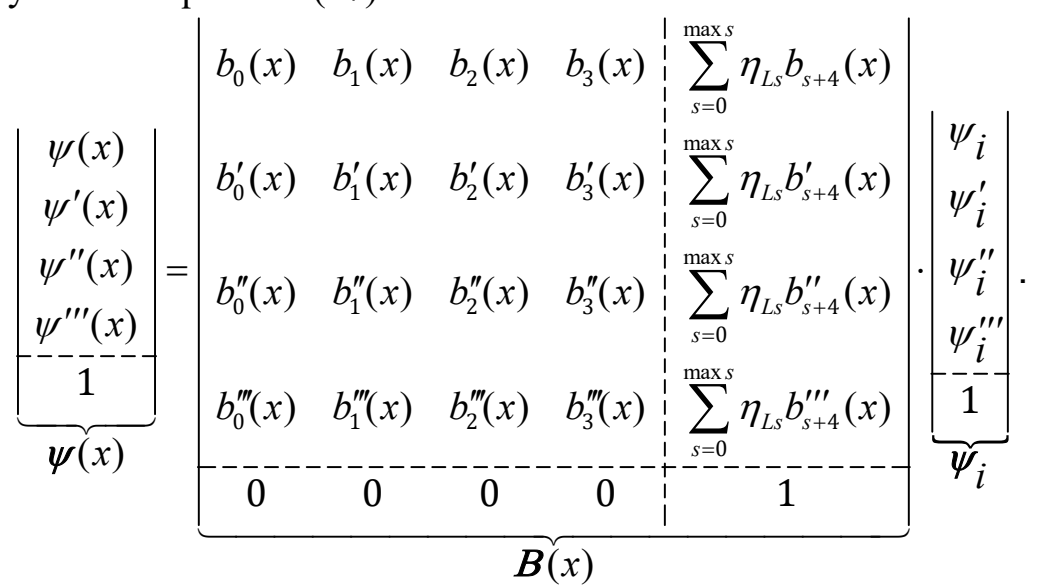

In equation (27), $\boldsymbol{B}(x)$ is a matrix, containing the solution functions of the homogeneous differential equation and particular solution functions of the inhomogeneous part of the differential equation and their first three derivatives at $x . \psi(x)$ is a vector, containing the angle of twist and its first three derivatives at $x$, and $\psi_{i}$ is a vector, obtained by specialization of $\psi(x)$ and its first three derivatives for the starting point $i$. The solution functions are calculated numerically by means of the algorithm published in [27].

\section{Relations in the framework of the transfer matrix method}

The transformation matrix $\boldsymbol{T}$ in the following matrix equation relates the vector $\psi(x)$ to the "static vector" $\boldsymbol{Z}(x)$, containing $\psi(x), \psi_{M}^{\prime}(x), M_{\omega}(x)$, and $M_{T}(x)$. This matrix equation is given as 


$$
\underbrace{\left|\begin{array}{c}
\psi(x) \\
\psi^{\prime}(x) \\
\psi^{\prime \prime}(x) \\
\psi^{\prime \prime \prime}(x) \\
\hdashline 1
\end{array}\right|}_{\psi(\boldsymbol{x})}=\underbrace{\left.\mid \begin{array}{llll:c}
t_{11} & t_{12} & t_{13} & t_{14} & t_{15} \\
t_{21} & t_{22} & t_{23} & t_{24} & t_{25} \\
t_{31} & t_{32} & t_{33} & t_{34} & t_{35} \\
t_{41} & t_{42} & t_{43} & t_{44} & t_{45} \\
\hdashline 0 & 0 & 0 & 0 & 1
\end{array}\right]}_{T} \cdot \underbrace{\mid \begin{array}{c}
\psi(x) \\
\psi_{M}^{\prime}(x) \\
M_{\omega}(x) \\
M_{T}(x) \\
\hdashline 1
\end{array}}_{\boldsymbol{Z ( x )}} .
$$

Details concerning determination of $\boldsymbol{T}$ are given in the Appendix.

By setting equation (28) equal to equation (29), the static vector $\boldsymbol{Z}(x)$ is obtained as

$$
\boldsymbol{Z}(x)=\boldsymbol{F}_{\boldsymbol{x i}}(x) \cdot \boldsymbol{Z}_{i}
$$

where $\boldsymbol{Z}_{i}$ is the static vector at the starting point $i$ and $\boldsymbol{F}_{\boldsymbol{x} i}(x)$ is the transfer matrix, given as

$$
\boldsymbol{F}_{x i}(x)=\left.\boldsymbol{T}^{-1}(x) \cdot \boldsymbol{B}(x) \cdot \boldsymbol{T}_{i}\right|_{x=0} .
$$

In addition,

$$
\underbrace{\left[\begin{array}{c}
\psi(x) \\
\psi_{M}^{\prime}(x) \\
M_{\omega}(x) \\
M_{T}(x) \\
\hdashline 1
\end{array}\right.}_{\boldsymbol{Z}(\boldsymbol{x})}=\underbrace{\left|\begin{array}{llll:l}
f_{11} & f_{12} & f_{13} & f_{14} & f_{15} \\
f_{21} & f_{22} & f_{23} & f_{24} & f_{25} \\
f_{31} & f_{32} & f_{33} & f_{34} & f_{35} \\
f_{41} & f_{42} & f_{43} & f_{44} & f_{45} \\
\hdashline 0 & 0 & 0 & 0 & 1
\end{array}\right|}_{\boldsymbol{F}_{x i}(\boldsymbol{x})} \cdot \underbrace{\left|\begin{array}{c}
\left.\psi_{i}\right|_{x=0} \\
\left.\psi_{M, i}^{\prime}\right|_{x=0} \\
\left.M_{\omega, i}\right|_{x=0} \\
\left.M_{T, i}\right|_{x=0} \\
\hdashline
\end{array}\right|}_{\boldsymbol{Z}_{i}}
$$

is obtained.

By neglecting the secondary torsion-moment deformation-effect and setting the warping constant equal to zero, equation (32) degenerates to the relation for SaintVenant torsion, including the influence of the variable axial force, resulting in a geometric stiffness. This gives

$$
\underbrace{\left[\begin{array}{c}
\psi(x) \\
M_{T}(x) \\
1
\end{array}\right.}_{\boldsymbol{Z}(\boldsymbol{x})}=\underbrace{\left[\begin{array}{cc:c}
b_{0}(x) & \frac{b_{1}(x)}{\left.G I_{T, i}^{*}\right|_{x=0}} & \sum_{s=0}^{\max s} \eta_{L s} b_{s+4}(x) \\
b_{0}(x) G I_{T}^{*} & \frac{b_{1}(x) G I_{T}^{*}(x)}{\left.G I_{T, i}^{*}\right|_{x=0}} & G I_{T}^{*}(x) \sum_{s=0}^{\max s} \eta_{L s} b_{s+4}^{\prime}(x) \\
\hdashline 0 & 0 & 1
\end{array} \mid\right.}_{\boldsymbol{F}_{x i}(\boldsymbol{x})} \cdot \underbrace{\left|\begin{array}{c}
\left.\psi_{i}\right|_{x=0} \\
\left.M_{T, i}\right|_{x=0} \\
\hdashline \\
\hdashline
\end{array}\right|}_{\boldsymbol{Z}_{i}} .
$$




\section{Finite beam element obtained from the transfer matrix method relations}

From the viewpoint of practical analysis there is no need for a transition from transfer matrix to a stiffness matrix for a beam element. Nevertheless, for the sake of completeness, such a transition is briefly described in the following.

Fig. 3 illustrates the beam element. It is loaded by the inertial torsional line moment $\rho(x) I_{p} \omega^{2} \psi(x)$ and the inertial line bimoment $\rho(x) I_{\omega} \omega^{2} \psi_{M}^{\prime}(x)$, the torsional line moment $m_{T}(x)$ and the torsional warping line moment $m_{\omega}(x)$ per unit length, where $I_{\omega}$ stands for the warping constant. These line moments represent the static equivalent of the respective dynamic action.

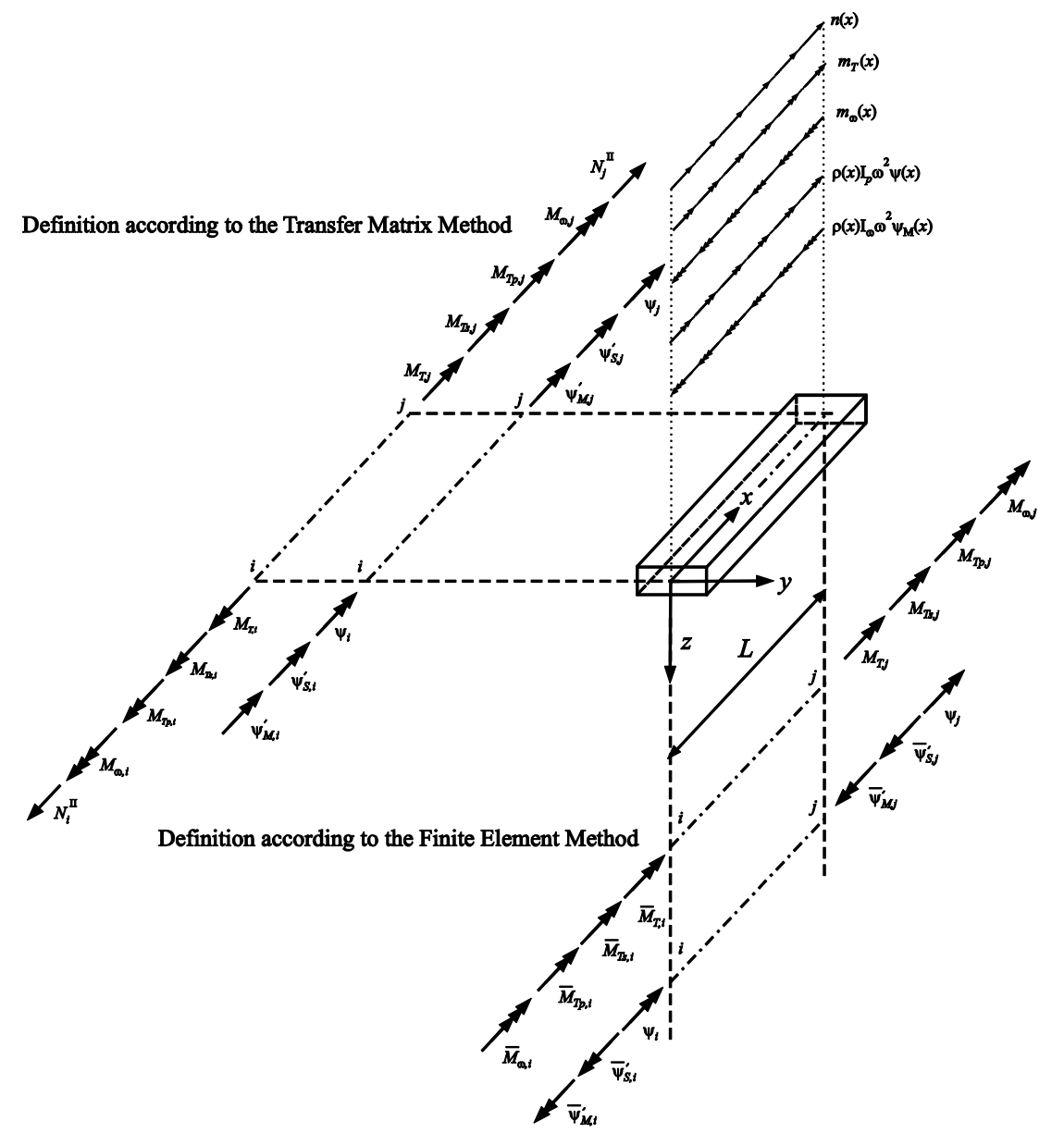

Fig. 3: Positive orientation of the axial force, the torsional moments, and the rotation angles at the element nodes for the transfer matrix method and the finite element method. 
The kinematic and kinetic variables at node $i$ are denoted by the index $i$ in (32) and in Fig. 3. By setting $x=L$ in (32), the dependence of the nodal variables at node $j$ on the nodal variables at node $i$ is obtained. Then, using appropriate mathematical operations, the local finite element equations for the second-order torsional warping theory read as follows (considering the definition of a positive coordinate system in the framework of the finite element method, resulting in $\bar{M}_{T, i}=-M_{T, i}$, $\bar{M}_{\omega, i}=-M_{\omega, i}, \bar{\psi}_{M, i}^{\prime}=-\psi_{M, i}^{\prime}$ and $\left.\bar{\psi}_{M, j}^{\prime}=-\psi_{M, j}^{\prime}\right)$ :

$$
\left|\begin{array}{c}
\bar{M}_{T, i} \\
\bar{M}_{\omega, i} \\
M_{T, j} \\
M_{\omega, j} \\
\hdashline 1
\end{array}\right|=\underbrace{\left.\mid \begin{array}{cccc:c}
K_{1,1} & K_{1,2} & K_{1,3} & K_{1,4} & K_{1,5} \\
K_{2,1} & K_{2,2} & K_{2,3} & K_{2,4} & K_{2,5} \\
K_{3,1} & K_{3,2} & K_{3,3} & K_{3,4} & K_{3,5} \\
K_{4,1} & K_{4,2} & K_{4,3} & K_{4,4} & K_{4,5} \\
\hdashline 0 & 0 & 0 & 0 & 1
\end{array}\right]}_{\boldsymbol{K}} \cdot\left|\begin{array}{c}
\psi_{i} \\
\bar{\psi}_{M, i}^{\prime} \\
\psi_{j} \\
\bar{\psi}_{M, j}^{\prime} \\
\hdashline 1
\end{array}\right|
$$

and

$$
\left|\begin{array}{c}
\bar{M}_{T, i} \\
\bar{M}_{\omega, i} \\
M_{T, j} \\
M_{\omega, j}
\end{array}\right|=\left|\begin{array}{cccc}
K_{1,1} & K_{1,2} & K_{1,3} & K_{1,4} \\
K_{2,1} & K_{2,2} & K_{2,3} & K_{2,4} \\
K_{3,1} & K_{3,2} & K_{3,3} & K_{3,4} \\
K_{4,1} & K_{4,2} & K_{4,3} & K_{4,4}
\end{array}\right| \cdot\left|\begin{array}{c}
\psi_{i} \\
\bar{\psi}_{M, i}^{\prime} \\
\psi_{j} \\
\bar{\psi}_{M, j}^{\prime}
\end{array}\right|+\left|\begin{array}{c}
K_{1,5} \\
K_{2,5} \\
K_{3,5} \\
K_{4,5}
\end{array}\right|,
$$

respectively.

The local finite element matrix $\boldsymbol{K}$ in (34) contains the linear and the geometric stiffness matrix and the consistent mass matrix.

By neglecting the secondary torsion-moment deformation-effect and by the setting warping constant equal to zero, equation (35) degenerates to the relations for SaintVenant torsion, including the influence of the variable axial force, resulting in a geometric stiffness. This gives

$$
\begin{aligned}
& \left|\begin{array}{c}
\bar{M}_{T, i} \\
M_{T, j}
\end{array}\right|=\left|\begin{array}{cc}
\left.\frac{b_{0}(x) G I_{T, i}^{*}}{b_{1}(x)}\right|_{x=L} & \left.\frac{-G I_{T, i}^{*}}{b_{1}(x)}\right|_{x=L} \\
\left.b_{0}(x) G I_{T}^{*}\right|_{x=L}-\frac{b_{1}^{\prime}(x) b_{0}(x) G I_{T}^{*}(x)}{b_{1}(x)} & \left.\frac{b_{1}^{\prime}(x) G I_{T}^{*}(x)}{b_{1}(x)}\right|_{x=L}
\end{array}\right| \cdot\left|\begin{array}{c}
\psi_{i} \\
\psi_{j}
\end{array}\right| \\
& +\left|\begin{array}{c}
\left.\frac{G I_{T, i}^{*} \sum_{s=0}^{\max s} \eta_{L s} b_{s+4}(x)}{b_{1}(x)}\right|_{x=L} \\
\left.G I_{T}^{*}(x)\left(\sum_{s=0}^{\max s} \eta_{L s} b_{s+4}^{\prime}(x)-\frac{b_{1}^{\prime}(x) \sum_{s=0}^{\max s} \eta_{L s} b_{s+4}(x)}{b_{1}(x)}\right)\right|_{x=L}
\end{array}\right| .
\end{aligned}
$$




\section{Numerical investigation}

The finite element relations were implemented into the software MATHEMATICA [28]. The numerical investigation includes modal and elastostatic torsional analyses of thin-walled beams.

In this Chapter, two kinds of modal and elastostatic analyses of beams with a variable axial force are considered. The described algorithm was implemented into the aforementioned software [28]. The results of the numerical experiments are presented in the Subchapters 6.1, 6.2 and 6.3.

\subsection{Modal analyses of a cantilever beam with an I cross-section, subjected to an axial load}

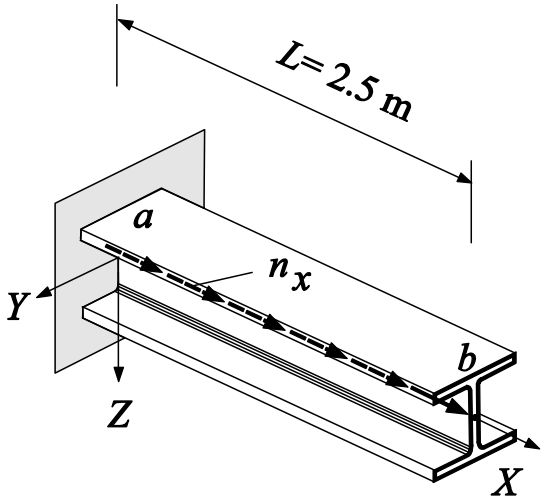

a)

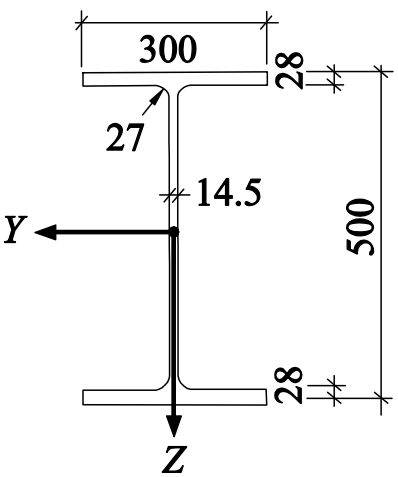

b)

Fig. 4: Cantilever beam with an I cross-section: a) system, axial line load, b) cross-section.

The length of the beam, $L$, is $2.5 \mathrm{~m}$. The cross-section is the one of a HEB-500 [29]. In Table 1 and Table 2, the material properties and the cross-sectional parameters, respectively, are listed. The axial, flexural, Saint-Venant torsional and warping eigenfrequencies, and the radius of gyration, are calculated for the cantilever beam for a variable axial force $N^{I I}(x)$, given as follows:

$$
N^{\mathrm{II}}(x)=n_{x}(L-x), \forall n_{x} \in[-3000,3000], \mathrm{kN} / \mathrm{m} .
$$

The calculation of the eigenfrequencies according to the second-order torsional warping theory with STMDE consists of the following steps: At first, the transfer matrix $\boldsymbol{F}_{x i}(x)$, see equation (32), is specialized for $L$ and for the nodes $a$ and $b$ (see Fig. 4). For modal analysis the influence of the load vector in the transfer matrix $\boldsymbol{F}_{b a}(x=L)$ is equal to zero. Taking the boundary conditions, given in equation (38), into account, the reduced system of two homogeneous algebraic equations is 
obtained. They represent an eigenvalue problem. The circular natural frequencies $\omega_{j}$ , $j=1,2, \ldots$, follow from the zeros of the determinant of the reduced system of equations. An iterative method was used to find these zeros [1]. The natural frequencies $f_{j}=\omega_{j} / 2 \pi, j=1,2, \ldots$, are computed subsequently.

In the same way, the calculation of the eigenfrequencies according to Saint-Venant torsion, including the influence of the variable axial-force effect is carried out.

The above algorithm was implemented into the software MATHEMATICA [28]. In this Subchapter, the results of the numerical experiments are presented and compared with the ones obtained by means of the available commercial software.

Table 1: Material properties.

\begin{tabular}{|c|c|c|}
\hline \multicolumn{3}{|c|}{ Material properties } \\
\hline Young's modulus & $E=21 \cdot 10^{7}$ & $\mathrm{kN} / \mathrm{m}^{2}$ \\
\hline Poisson's ratio & $v=0.3$ & \\
\hline Shear modulus & $G=8.0769 \cdot 10^{7}$ & $\mathrm{kN} / \mathrm{m}^{2}$ \\
\hline Mass density & $\rho=7.85$ & $\mathrm{t} / \mathrm{m}^{3}$ \\
\hline
\end{tabular}

Table 2: Cross-sectional parameters [29].

\begin{tabular}{|c|c|c|}
\hline \multicolumn{2}{|c|}{ Cross-sectional parameters [29] } \\
\hline Cross-sectional area & $A=239 \cdot 10^{-4}$ & $\mathrm{~m}^{2}$ \\
\hline Shear area in the $y$ - direction & $A_{y}=140.27 \cdot 10^{-4}$ & $\mathrm{~m}^{2}$ \\
\hline Shear area in the $z$ - direction & $A_{z}=65.77 \cdot 10^{-4}$ & $\mathrm{~m}^{2}$ \\
\hline Second moment of area about the $y$-axis & $I_{y}=107200 \cdot 10^{-8}$ & $\mathrm{~m}^{4}$ \\
\hline Second moment of area about the $z$-axis & $I_{z}=12620 \cdot 10^{-8}$ & $\mathrm{~m}^{4}$ \\
\hline Polar moment of area & $I_{p}=I_{y}+I_{z}=119820 \cdot 10^{-8}$ & $\mathrm{~m}^{4}$ \\
\hline Radius of gyration & $i_{p}=22.41 \cdot 10^{-2}$ & $\mathrm{~m}$ \\
\hline Torsion constant & $I_{T}=538.4 \cdot 10^{-8}$ & $\mathrm{~m}^{4}$ \\
\hline Secondary torsion constant & $I_{T s}=77974.4 \cdot 10^{-8}$ & $\mathrm{~m}^{4}$ \\
\hline Warping constant & $I_{\omega}=7017700 \cdot 10^{-12}$ & $\mathrm{~m}^{6}$ \\
\hline
\end{tabular}

The following boundary conditions are applied:

a) Saint-Venant torsional vibrations:

$$
\left.\psi(x)\right|_{x=0}=\psi_{a}=0,\left.M_{T}(x)\right|_{x=L}=M_{T, b}=0 .
$$

b) Warping vibrations:

$$
\left.\psi(x)\right|_{x=0}=\psi_{a}=0,\left.\quad \psi_{M}^{\prime}(x)\right|_{x=0}=\psi_{M, a}^{\prime}=0,
$$




$$
\left.M_{\omega}(x)\right|_{x=L}=M_{\omega, b}=0,\left.\quad M_{T}(x)\right|_{x=L}=M_{T, b}=0 .
$$

Table 3 and Table 4 contain a comparison of the results for the first three torsional eigenfrequencies, obtained by the proposed method (Saint-Venant torsion and second-order torsional warping theory with STMDE), with corresponding results, obtained by the computer programs ANSYS [3], RSTAB [30], and RFEM [33].

The computational models for the proposed method (Saint-Venant and warping torsion) consisted of only one finite beam element. Alternatively, 100 beam elements of RSTAB [30] were used for Saint-Venant modal analysis. This element does not allow consideration of a variable axial force. A very fine mesh, consisting of 16080 3D and 2D - Solid finite elements was used in the analysis by ANSYS [3], and 100 3D-Solid elements were used in the analysis RFEM [33]. The variation of the axial force in the 3D-Solid model was considered by applying mechanicaly consistent forces to the nodes of the elements.

The eigenfrequencies and eigenmodes obtained by ANSYS [3] with 16080 Solid186 elements contain modes with deformations of the walls (Fig. 5). This effect can not be considered by the proposed method and by finite beam elements. Table 3 and Table 4 contain only torsional eigenfrequencies and thus, disregards results as shown in Fig. 5.

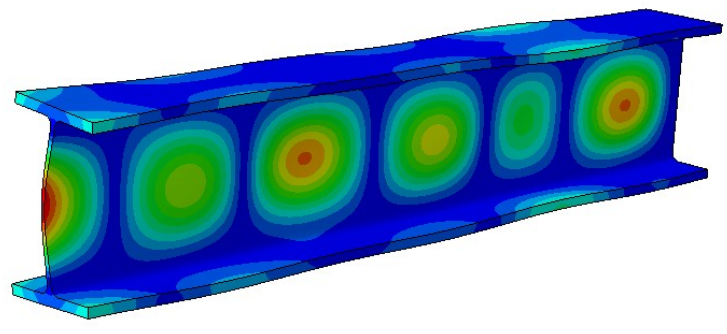

Fig. 5: Eigenmode obtained by ANSYS [3] with SOLID186 elements showing deformations of the walls.

Table 3 and Table 4 show a comparison of the results for the eigenfrequencies for a cantilever beam with an I cross-section and a varyiable axial force $N^{\mathrm{II}}(x)=n_{x}(L-x), \forall n_{x} \in[-3000,3000], \mathrm{kN} / \mathrm{m}$. They were obtained by the proposed method, using only one element, by RSTAB [30] 100 beams-elements, RFEM [33] 100 2D-Solid elements, with corresponding results, obtained by ANSYS [3] 16080 SOLID 186 elements. 
Table 3: Comparison of the results for the eigenfrequencies obtained by the proposed method, by RSTAB [30] 100 beams-elements, RFEM [33] 100 2D-Solid elements, with corresponding results, obtained by ANSYS [3] 16080 SOLID 186 elements, for a cantilever beam with an I cross-section and a variable axial force.

\begin{tabular}{|c|c|c|c|c|c|c|c|}
\hline \multicolumn{3}{|c|}{$\begin{array}{l}\text { eigenfrequencies for a } \\
\text { variable axial force } \\
\begin{array}{c}N^{\mathrm{II}}(x)=n_{x}(L-x) \\
\forall n_{x} \in\end{array} \\
{[0,3000]\left[\frac{\mathrm{kN}}{\mathrm{m}}\right]}\end{array}$} & \multirow[t]{2}{*}{ 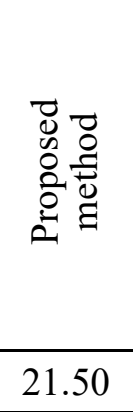 } & \multirow[t]{2}{*}{ 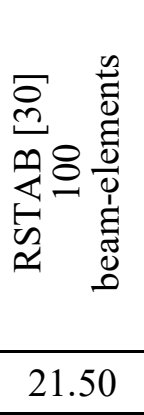 } & \multirow[t]{2}{*}{ 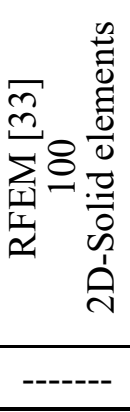 } & \multirow[t]{2}{*}{ 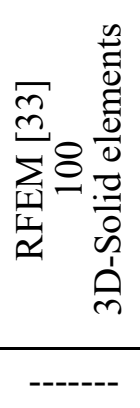 } & \multirow[t]{2}{*}{ 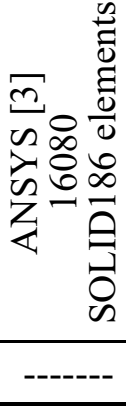 } \\
\hline \multirow{3}{*}{\multicolumn{2}{|c|}{ 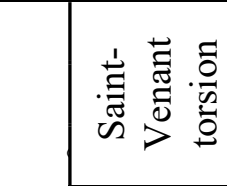 }} & $\mathrm{f}_{1}=$ & & & & & \\
\hline & & $f_{2}=$ & 64.51 & 64.51 & ------ & ------ & ------ \\
\hline & & $f_{3}=$ & 107.51 & 107.54 & ------- & ------- & ------- \\
\hline \multirow{3}{*}{\multicolumn{2}{|c|}{ 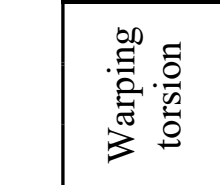 }} & $\mathrm{f}_{1}=$ & 45.21 & ------- & 42.37 & 43.81 & 43.26 \\
\hline & & $f_{2}=$ & 220.16 & ------- & 218.89 & 216.56 & 215.24 \\
\hline & & $f_{3}=$ & 546.70 & ------- & 552.78 & 555.81 & 553.49 \\
\hline & \multirow{3}{*}{ 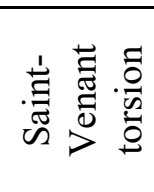 } & $f_{1}=$ & 23.55 & 21.50 & ------- & ------- & ------- \\
\hline & & $f_{2}=$ & 69.07 & 64.51 & ------- & ------ & ------- \\
\hline & & $f_{3}=$ & 114.90 & 107.54 & ------- & ------- & ------- \\
\hline & \multirow{3}{*}{ 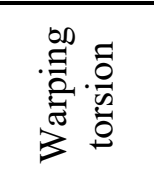 } & $f_{1}=$ & 46.12 & ------- & 43.34 & 44.69 & 43.83 \\
\hline & & $f_{2}=$ & 221.19 & ------- & 217.53 & 219.87 & 215.72 \\
\hline & & $f_{3}=$ & 547.88 & ------- & 553.89 & 556.49 & 553.91 \\
\hline \multirow{6}{*}{ 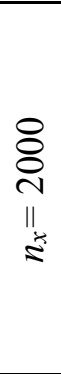 } & \multirow{3}{*}{ 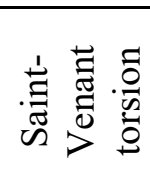 } & $f_{1}=$ & 25.38 & 21.50 & ------- & ------- & ------- \\
\hline & & $f_{2}=$ & 73.16 & 64.51 & ------- & ------- & ------- \\
\hline & & $f_{3}=$ & 121.51 & 107.54 & ------ & ------ & ------ \\
\hline & \multirow{3}{*}{ 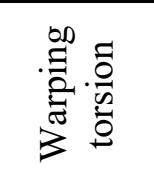 } & $f_{1}=$ & 47.02 & ------- & 44.28 & 45.56 & 44.42 \\
\hline & & $f_{2}=$ & 222.22 & ------- & 218.51 & 220.84 & 216.33 \\
\hline & & $f_{3}=$ & 549.05 & ------- & 555.05 & 557.58 & 554.70 \\
\hline & \multirow{3}{*}{ 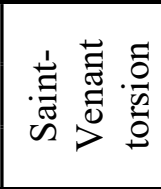 } & $f_{1}=$ & 27.06 & 21.50 & ------ & ------ & ------ \\
\hline & & $f_{2}=$ & 76.89 & 64.51 & ------- & ------- & ------- \\
\hline & & $f_{3}=$ & 127.54 & 107.54 & ------ & ------ & ------ \\
\hline & \multirow{3}{*}{ 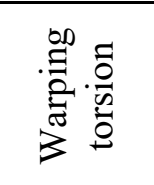 } & $f_{1}=$ & 47.89 & ------- & 45.21 & 46.41 & 44.96 \\
\hline & & $f_{2}=$ & 223.24 & ------- & 219.48 & 221.81 & 216.93 \\
\hline & & $f_{3}=$ & 550.22 & ------- & 556.21 & 558.66 & 555.48 \\
\hline
\end{tabular}


Table 4: Comparison of the results for the eigenfrequencies obtained by the proposed method, by RSTAB [30] 100 beams-elements, RFEM [33] 100 2D-Solid elements, with corresponding results, obtained by ANSYS [3] 16080 SOLID 186 elements, for a cantilever beam with an I cross-section and a variable axial force.

\begin{tabular}{|c|c|c|c|c|c|c|c|}
\hline \multicolumn{3}{|c|}{$\begin{array}{l}\text { eigenfrequencies for a } \\
\text { variable axial force } \\
\begin{array}{c}N^{\mathrm{II}}(x)=n_{x}(L-x) \\
\forall n_{x} \in\end{array} \\
{[0,-3000]\left[\frac{\mathrm{kN}}{\mathrm{m}}\right]}\end{array}$} & \multirow[t]{2}{*}{ 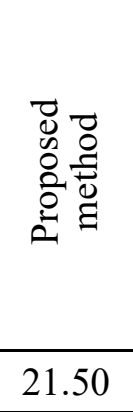 } & \multirow[t]{2}{*}{ 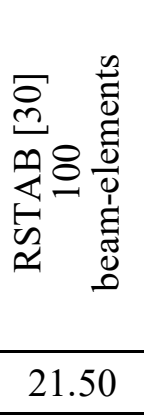 } & \multirow[t]{2}{*}{ 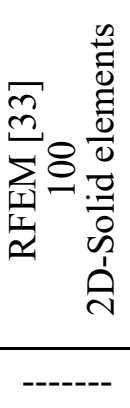 } & \multirow[t]{2}{*}{ 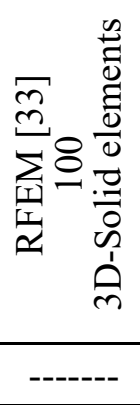 } & \multirow[t]{2}{*}{ 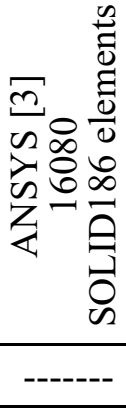 } \\
\hline \multirow{3}{*}{\multicolumn{2}{|c|}{ 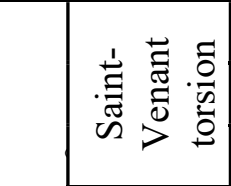 }} & $f_{1}=$ & & & & & \\
\hline & & $f_{2}=$ & 64.51 & 64.51 & ------ & ------ & ------ \\
\hline & & $f_{3}=$ & 107.51 & 107.54 & ------- & ------- & ------- \\
\hline \multirow{3}{*}{\multicolumn{2}{|c|}{ 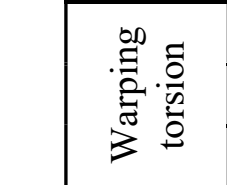 }} & $\mathrm{f}_{1}=$ & 45.21 & ------- & 42.37 & 43.81 & 43.26 \\
\hline & & $f_{2}=$ & 220.16 & ------- & 218.89 & 216.56 & 215.24 \\
\hline & & $f_{3}=$ & 546.70 & ------- & 552.78 & 555.81 & 553.49 \\
\hline & \multirow{3}{*}{ 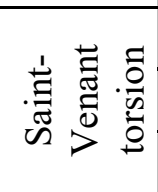 } & $f_{1}=$ & 19.14 & 21.50 & ------- & ------- & ------- \\
\hline & & $f_{2}=$ & 59.24 & 64.51 & ------- & ------- & ------- \\
\hline & & $f_{3}=$ & 98.96 & 107.54 & ------- & ------- & ------- \\
\hline & \multirow{3}{*}{ 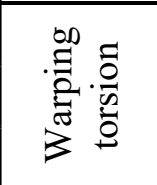 } & $f_{1}=$ & 44.28 & ------- & 41.38 & 42.90 & 42.63 \\
\hline & & $f_{2}=$ & 219.12 & ------- & 217.93 & 215.56 & 214.49 \\
\hline & & $f_{3}=$ & 545.52 & ------- & 551.56 & 554.32 & 552.34 \\
\hline \multirow{6}{*}{ 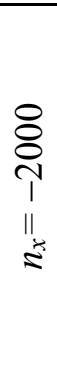 } & \multirow{3}{*}{ 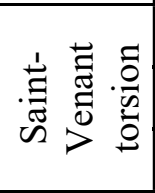 } & $f_{1}=$ & 16.23 & 21.50 & ------- & ------- & ------- \\
\hline & & $f_{2}=$ & 52.74 & 64.51 & ------- & ------- & ------- \\
\hline & & $f_{3}=$ & 88.41 & 107.54 & ------ & ------- & - ----- \\
\hline & \multirow{3}{*}{ 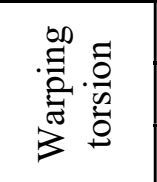 } & $f_{1}=$ & 43.33 & ------- & 40.37 & 41.97 & 42.02 \\
\hline & & $f_{2}=$ & 218.08 & ------- & 215.96 & 214.56 & 213.86 \\
\hline & & $f_{3}=$ & 544.33 & ------- & 550.39 & 553.23 & 551.55 \\
\hline & \multirow{3}{*}{ 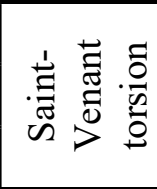 } & $f_{1}=$ & 11.92 & 21.50 & ------ & ------ & ------ \\
\hline & & $f_{2}=$ & 43.16 & 64.51 & ------- & ------- & ------ \\
\hline & & $f_{3}=$ & 72.88 & 107.54 & ------ & - ---- & ------ \\
\hline & \multirow{3}{*}{ 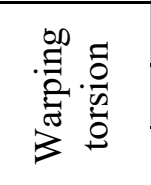 } & $f_{1}=$ & 42.35 & ------- & 39.32 & 41.02 & 41.39 \\
\hline & & $f_{2}=$ & 217.03 & ------- & 215.99 & 213.67 & 213.24 \\
\hline & & $f_{3}=$ & 543.14 & ------- & 549.22 & 552.14 & 550.76 \\
\hline
\end{tabular}


As shown in Table 3 and Table 4, the eigenfrequencies obtained by the proposed second-order torsional warping elements agree very well with the ones obtained with 3D-Solid elememts. As expected, the Saint Venant solution (with and without the axial force effect) gave incorrect results.

Analogous to the situation for bending vibrations, axial tension in addition to torsion results in an increase and axial compression in addition to torsion in a decrease of the torsional eigenfrequencies.

Fig. 6 shows the results for the first three torsional eigenfrequencies for SaintVenant torsion, including the influence of the variable axial force, as obtained by the proposed method, see equation (36), and by RSTAB [30] ", but without the influence of a variable axial force," for a cantilever beam with an I cross-section and a variable axial force $N^{\mathrm{II}}(x)=n_{x}(L-x), \forall n_{x} \in[-3000,3000] \quad[\mathrm{kN} / \mathrm{m}]$. The difference between the results from both methods increases with, increasing number of the eigenfrequency. For the case $n(x)=0$, the eigenfrequencies obtained by the two approaches are the same.

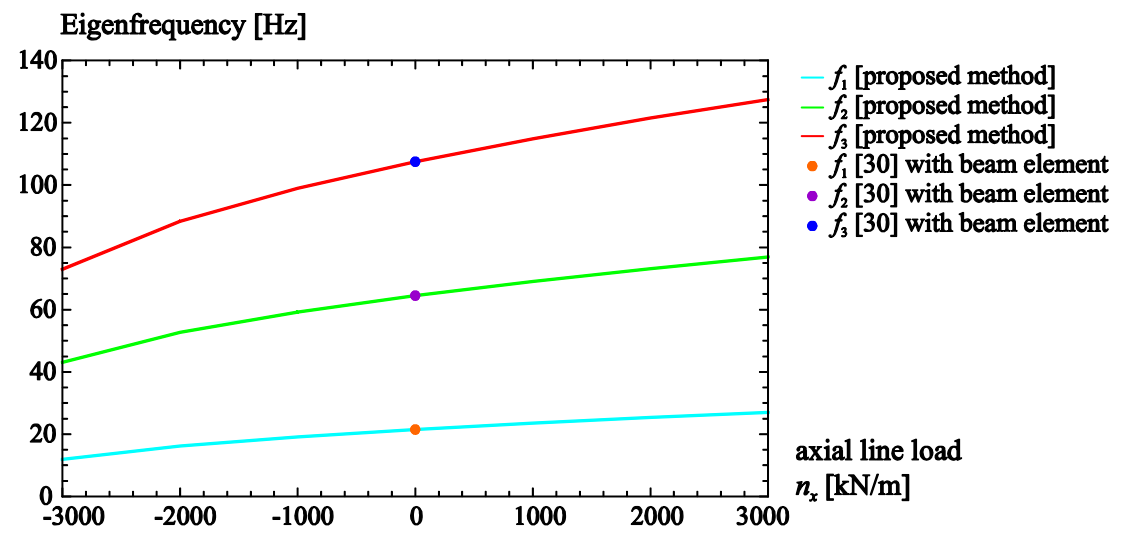

Fig. 6: Comparison of the first three torsional eigenfrequencies (Saint-Venant torsion), obtained by the proposed method (second row in the table 6) and obtained by RSTAB [30] 100 beams-elements (third row in the table 6), for a cantilever beam with an I cross-section and a variable axial force.

\subsection{Elastostatic analyses of a cantilever beam with an I cross-section and variable axial forces}

The length of the beam, $L$, is $2.5 \mathrm{~m}$. The cross-section is the one of a HEB-500 [29] with no rounded corners. In Table 1 and Table 5, the material properties and the crosssectional parameters, respectively, are listed. The elastostatic analyses are performed for a cantilever beam, subjected to a variable axial force $N^{\mathrm{II}}(x)=n_{x}(L-x), \forall n_{x} \in$ $[-3000,3000]$ according to equation (37). The boundary torsional moment at point $b$ is given as $M_{T, b}=10 \mathrm{kNm}$. 


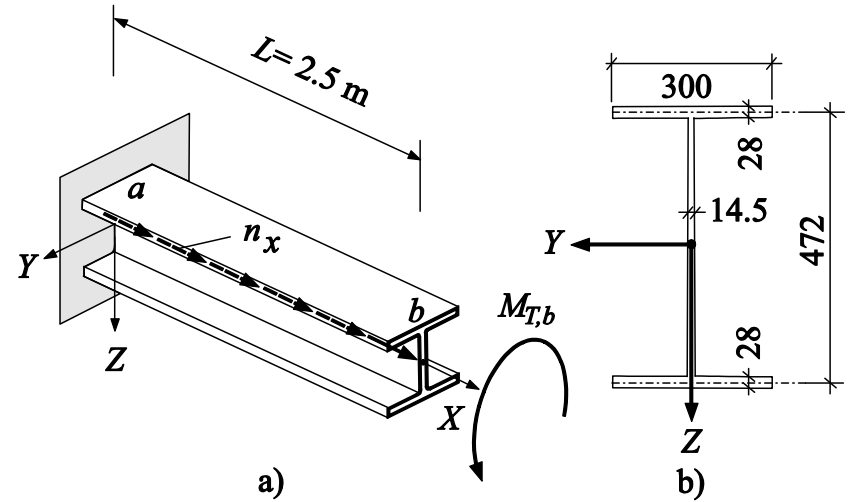

Fig. 7: Cantilever beam with an I cross-section: a) system, axial line load, torsional moment, b) cross-section.

The following boundary conditions are applied:

a) Saint-Venant torsion:

$$
\left.\psi(x)\right|_{x=0}=\psi_{a}=0,\left.M_{T}(x)\right|_{x=L}=M_{T, b}=10[\mathrm{kNm}] .
$$

b) Second-order torsional warping theory:

$$
\begin{gathered}
\left.\psi(x)\right|_{x=0}=\psi_{a}=0,\left.\quad \psi_{M}^{\prime}(x)\right|_{x=0}=\psi_{M, a}^{\prime}=0, \\
\left.M_{\omega}(x)\right|_{x=L}=M_{\omega, b}=0,\left.\quad M_{T}(x)\right|_{x=L}=M_{T, b}=10[\mathrm{kNm}] .
\end{gathered}
$$

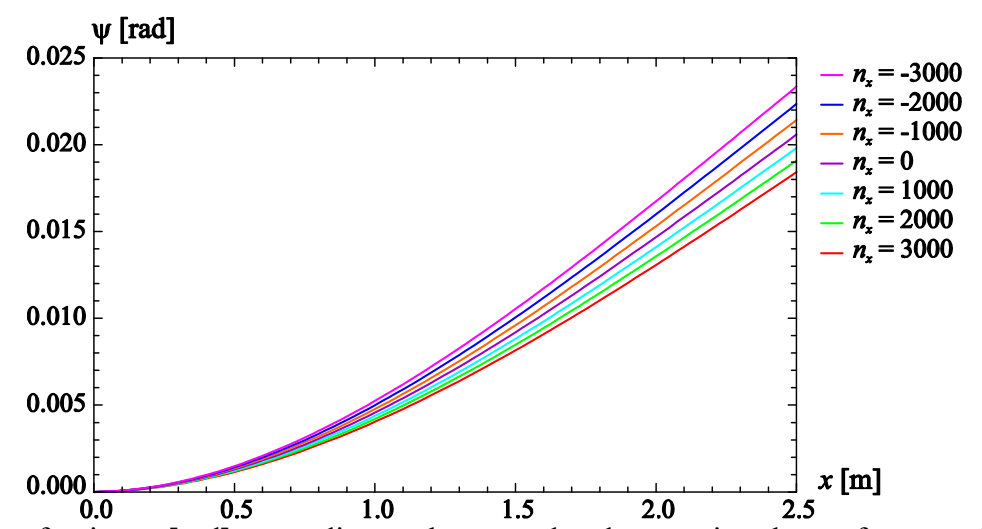

Fig. 8: Angle of twist, $\psi$ [rad], according to the second-order warping theory for a cantilever beam of length $L=2.5 \mathrm{~m}$, subjected to the torsion-moment $M_{T, b}=10 \mathrm{kNm}$ and to a variable axial force $N^{\mathrm{II}}(x)=n_{x}(L-x), \forall n_{x} \in[-3000,3000],[\mathrm{kN} / \mathrm{m}]$. 


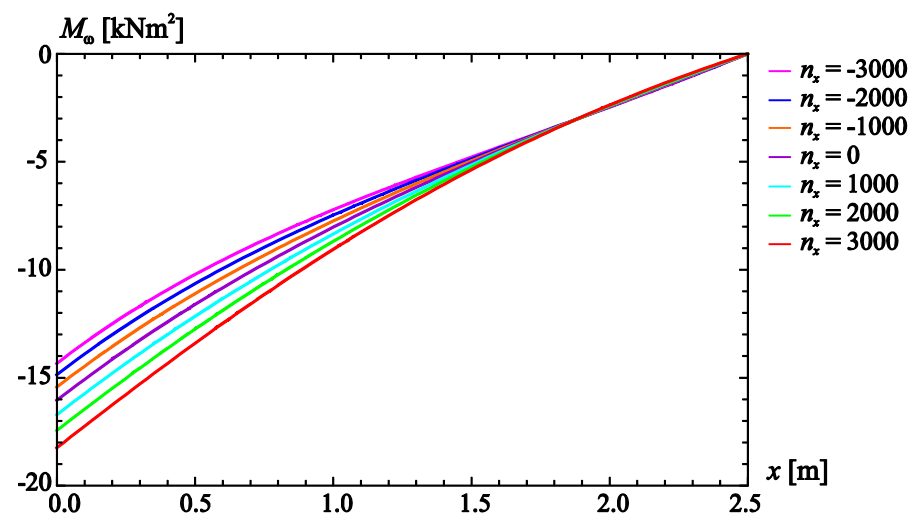

Fig. 9: Warping moment, $M_{\omega}\left[\mathrm{kNm}^{2}\right]$, according to the second-order warping theory for a cantilever beam of length $L=2.5 \mathrm{~m}$, subjected to the torsion-moment $M_{T, b}=10 \mathrm{kNm}$ and to a variable axial force $N^{\mathrm{II}}(x)=n_{x}(L-x), \forall n_{x} \in[-3000,3000],[\mathrm{kN} / \mathrm{m}]$.

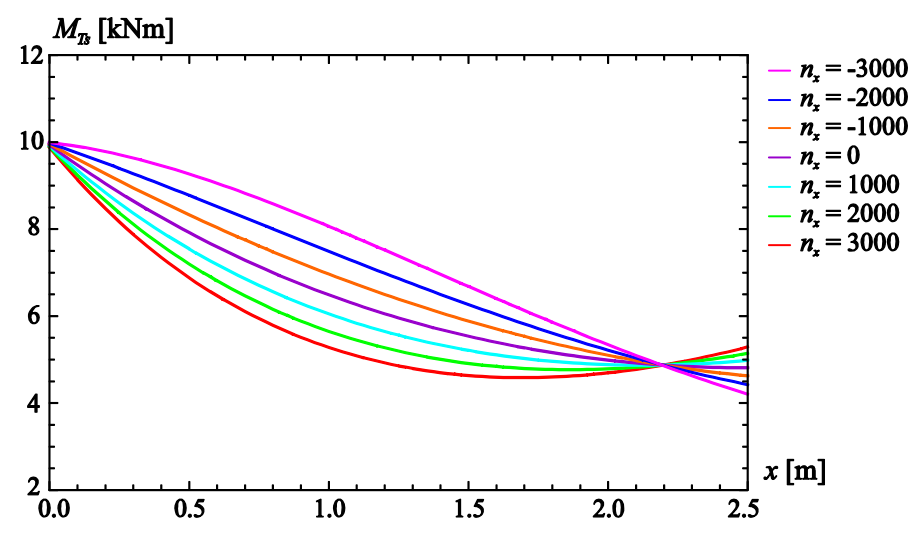

Fig. 10: Secondary torsional moment, $M_{T s}[\mathrm{kNm}]$, according to the second-order warping theory for a cantilever beam of length $L=2.5 \mathrm{~m}$, subjected to the torsion-moment $M_{T, b}=10 \mathrm{kNm}$ and to a variable axial force $N^{\mathrm{II}}(x)=n_{x}(L-x), \forall n_{x} \in[-3000,3000],[\mathrm{kN} / \mathrm{m}]$.

As shown in Fig. 10 and Fig. 11, at the point with the coordinate $x=2.267$ [m], where the individual curves are intersecting, the primary torsional moment and the secondary torsional moment are obtained as $M_{T p}=M_{T S}=\frac{M_{T}}{2}=5[\mathrm{kNm}]$, and they are independent of the axial forces. 


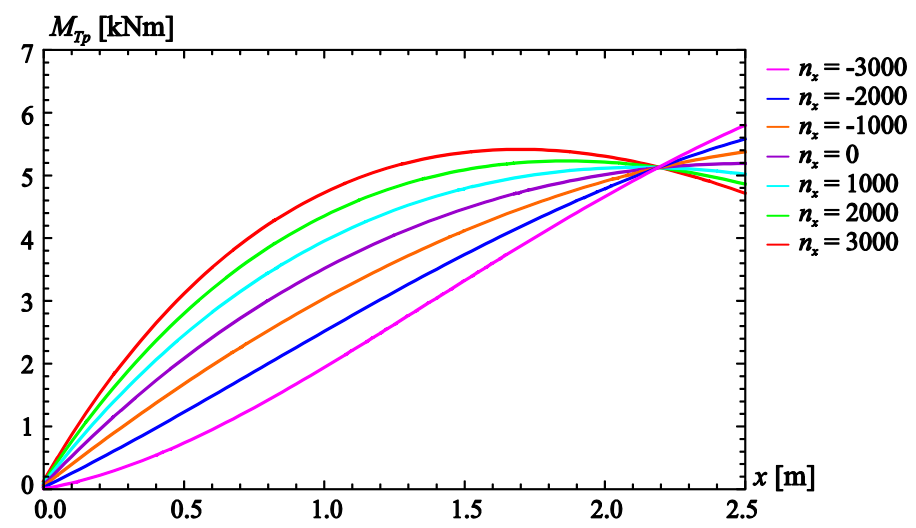

Fig. 11: Primary torsional moment, $M_{T p}[\mathrm{kNm}]$, according to the second-order warping theory for a cantilever beam of length $L=2.5 \mathrm{~m}$, subjected to the torsion-moment $M_{T, b}=10 \mathrm{kNm}$ and to a variable axial force $N^{\mathrm{II}}(x)=n_{x}(L-x), \forall n_{x} \in[-3000,3000]$, [kN/m].

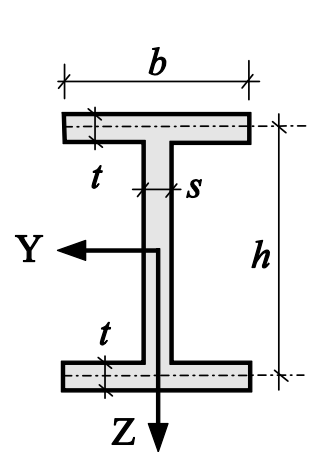

a)

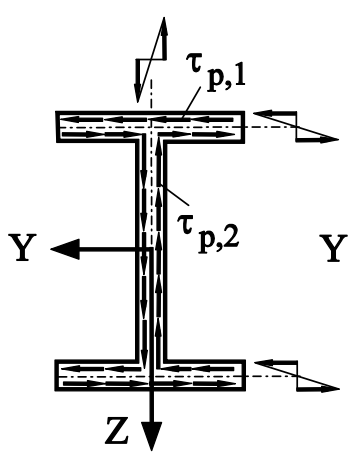

b)

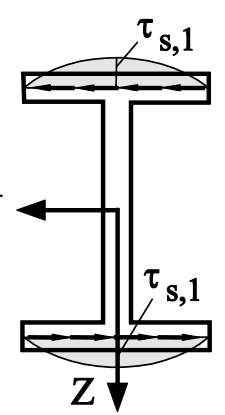

c)

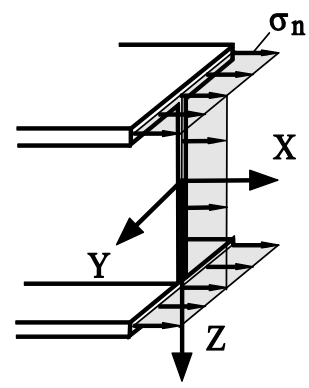

d)

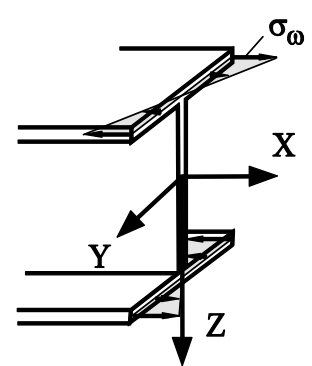

e)

Fig. 12: a) Cross-section, b) primary shear stress, c) secondary shear stress, d) axial stress according to axial forces, e) axial stress due to warping

Table 5 contains the cross-sectional parameters, which are taken from [32]. 
Table 5: Cross-sectional parameters [32].

\begin{tabular}{|c|c|c|}
\hline Torsion constant & $I_{T}=4764 \cdot 10^{-9}$ & $\mathrm{~m}^{4}$ \\
\hline Secondary torsion constant & $I_{T S}=7609 \cdot 10^{-7}$ & $\mathrm{~m}^{4}$ \\
\hline Warping constant & $I_{\omega}=68481 \cdot 10^{-10}$ & $\mathrm{~m}^{6}$ \\
\hline Warping-ordinate at the corner points & $\left|\omega_{R}\right|=3.54 \cdot 10^{-2}$ & $\mathrm{~m}^{2}$ \\
\hline Radius of gyration & $i_{p}=22.41 \cdot 10^{-2}$ & $\mathrm{~m}$ \\
\hline
\end{tabular}

The equations (42)-(46) are taken from [32].

$$
\begin{gathered}
A_{S}=s h, \quad A_{G}=t b-\frac{s t}{2}, \quad A=2 A_{G}+A_{S}, \quad \omega_{R}=\frac{b h}{4}, \\
I_{T}=\frac{1}{3}\left(2 A_{G} t^{2}+A_{S} s^{2}\right), I_{\omega}=\omega_{R}^{2} \frac{2 A_{G}}{3}, I_{T s}=\frac{A_{G} h^{2}}{2.4}
\end{gathered}
$$

The axial stresses due to the warping moment at the corner points are given as follows:

$$
\sigma_{\omega}= \pm \frac{M_{\omega}}{I_{\omega}} \omega_{R} \text {. }
$$

The total axial stresses at corner points are obtained as

$$
\sigma_{\text {total }}=\sigma_{n} \pm \sigma_{\omega}, \text { where } \sigma_{n}=\frac{N}{A} .
$$

The shear stress resulting from the secondary moment is given as

$$
\tau_{s, 1}=1.5 \frac{M_{T S}}{t h b} .
$$

The shear stresses resulting from the primary moment are given as

$$
\tau_{p, 1}=\frac{M_{T p}}{I_{T}^{*}} t, \quad \tau_{p, 2}=\frac{M_{T p}}{I_{T}^{*}} s, \text { with } I_{T}^{*}(x)=\frac{G I_{T}+N^{I I}(x) i_{p}^{2}}{G} .
$$

According to Fig. 12, the total shear stresses are obtained as follow:

$$
\tau_{1}^{\text {total }}=\tau_{s, 1}+\tau_{p, 1}, \quad \tau_{2}^{\text {total }}=\tau_{p, 2}
$$

Table 6 contains the values of the axial force $N^{I I}$, the bimoment $M_{\omega}$, the torsional moment $M_{T}$, the primary torsional moment $M_{T p}$, the secondary torsional moment $M_{T S}$, and the angle of twist, $\psi(x)$, at $x=1 \mathrm{~m}$, obtained by the proposed method, using only one element for a cantilever beam of length $L=2.5 \mathrm{~m}$, subjected to the torsion-moment $M_{T, b}=10 \mathrm{kNm}$ and to a variable axial force $N^{\mathrm{II}}(x)=n_{x}(L-x)$, $\forall n_{x} \in[-3000,3000][\mathrm{kN} / \mathrm{m}]$. 
Table 6: Value of the axial force, the bimoment, the primary torsional moment, the secondary torsional moment, and the angle of twist at $x=1 \mathrm{~m}$, obtained by the proposed method.

\begin{tabular}{|c|c|c|c|c|c|c|}
\hline $\begin{array}{c}n_{x} \\
{[\mathrm{kN} / \mathrm{m}]}\end{array}$ & $\begin{array}{c}N \\
{[\mathrm{kN}]}\end{array}$ & $\begin{array}{c}M_{\omega} \\
{\left[\mathrm{kNm}^{2}\right]}\end{array}$ & $\begin{array}{c}M_{T} \\
{[\mathrm{kNm}]}\end{array}$ & $\begin{array}{c}M_{T p} \\
{[\mathrm{kNm}]}\end{array}$ & $\begin{array}{c}M_{T s} \\
{[\mathrm{kNm}]}\end{array}$ & $\begin{array}{c}\psi .1000 \\
{[\mathrm{Rad}]}\end{array}$ \\
\hline 3000 & 4500 & -7.520 & 10 & 4.614 & 5.386 & 4.2598 \\
\hline 2000 & 3000 & -7.797 & 10 & 4.217 & 5.783 & 4.4402 \\
\hline 1000 & 1500 & -8.095 & 10 & 3.784 & 6.216 & 4.6359 \\
\hline 0 & 0 & -8.419 & 10 & 3.311 & 6.690 & 4.8490 \\
\hline-1000 & -1500 & -8.771 & 10 & 2.791 & 7.209 & 5.0818 \\
\hline-2000 & -3000 & -9.155 & 10 & 2.218 & 7.782 & 5.3372 \\
\hline-3000 & -4500 & -9.577 & 10 & 1.584 & 8.416 & 5.6185 \\
\hline
\end{tabular}

Table 7 permits a comparison of the results for the total axial stress at $x=1 \mathrm{~m}$, obtained by the proposed method, with corresponding results, obtained by means of ABAQUS/CAE [5] 92960 Elements, Type: C3D8RH for a cantilever beam of length $L=2.5 \mathrm{~m}$, subjected to the torsion-moment $M_{T, b}=10 \mathrm{kNm}$ and to a variable axial force $N^{\mathrm{II}}(x)=n_{x}(L-x), \forall n_{x} \in[-3000,3000][\mathrm{kN} / \mathrm{m}]$. The results for the normal stress, obtained by the two methods, agree very well.

Table 7: Total axial stress at $x=1 \mathrm{~m}$, obtained by the proposed method and by [5].

\begin{tabular}{|c|c|c|c|c|c|c|}
\hline $\begin{array}{c}n_{x} \\
{[\mathrm{kN} / \mathrm{m}]}\end{array}$ & $\begin{array}{c}\sigma_{n} \\
{\left[\mathrm{~N} / \mathrm{mm}^{2}\right]} \\
\text { obtained } \\
\text { by the } \\
\text { proposed } \\
\text { method }\end{array}$ & $\begin{array}{c}\sigma_{\omega} \\
{\left[\mathrm{N} / \mathrm{mm}^{2}\right]} \\
\text { obtained } \\
\text { by the } \\
\text { proposed } \\
\text { method }\end{array}$ & $\begin{array}{c}\min \sigma \\
{\left[\mathrm{N} / \mathrm{mm}^{2}\right]} \\
\text { obtained } \\
\text { by the } \\
\text { proposed } \\
\text { method }\end{array}$ & $\begin{array}{c}\max \sigma \\
{\left[\mathrm{N} / \mathrm{mm}^{2}\right]} \\
\text { obtained } \\
\text { by the } \\
\text { proposed } \\
\text { method }\end{array}$ & $\begin{array}{c}\min \sigma \\
{\left[\mathrm{N} / \mathrm{mm}^{2}\right]} \\
\text { obtained } \\
\text { by [5] }\end{array}$ & $\begin{array}{c}\max \sigma \\
{\left[\mathrm{N} / \mathrm{mm}^{2}\right]} \\
\text { obtained } \\
\text { by [5] }\end{array}$ \\
\hline 3000 & 193.648 & -38.875 & 154.773 & 232.524 & 155.280 & 234.300 \\
\hline 2000 & 129.099 & -40.304 & 88.795 & 169.403 & 89.300 & 169.600 \\
\hline 1000 & 64.549 & -41.847 & 22.703 & 106.396 & 23.300 & 106.007 \\
\hline 0 & 0 & -43.519 & -43.519 & 43.519 & -43.770 & 43.770 \\
\hline-1000 & -64.549 & -45.338 & -109.888 & -19.211 & -110.800 & -19.400 \\
\hline-2000 & -129.099 & -47.326 & -176.424 & -81.773 & -177.400 & -81.600 \\
\hline-3000 & -193.648 & -49.505 & -243.154 & -144.143 & -244.600 & -143.900 \\
\hline
\end{tabular}

Table 8 permits a comparison of the results for the total shear stress at $x=1 \mathrm{~m}$, obtained by the proposed method, with corresponding results, obtained by means of ABAQUS/CAE [5] 92960 Elements, Type: C3D8RH, for a cantilever beam of length $L=2.5 \mathrm{~m}$, subjected to the torsion-moment $M_{T, b}=10 \mathrm{kNm}$, and to the variable axial force $N^{\mathrm{II}}(x)=n_{x}(L-x), \forall n_{x} \in[-3000,3000][\mathrm{kN} / \mathrm{m}]$. The results for the shear stress obtained by the two methods agree very well.

Table 8: Total shear stress at $x=1 \mathrm{~m}$, obtained by the proposed method and by [5]. 


\begin{tabular}{|c|c|c|c|c|c|c|c|}
\hline $\begin{array}{c}n_{x} \\
{[\mathrm{kN} / \mathrm{m}]}\end{array}$ & $\begin{array}{c}\tau_{p 1} \\
{\left[\mathrm{~N} / \mathrm{mm}^{2}\right]} \\
\text { obtained } \\
\text { by the } \\
\text { proposed } \\
\text { method }\end{array}$ & $\begin{array}{c}\tau_{p 2} \\
{\left[\mathrm{~N} / \mathrm{mm}^{2}\right]} \\
\text { obtained } \\
\text { by the } \\
\text { proposed } \\
\text { method }\end{array}$ & $\begin{array}{c}\tau_{s 1} \\
{\left[\mathrm{~N} / \mathrm{mm}^{2}\right]} \\
\text { obtained } \\
\text { by the } \\
\text { proposed } \\
\text { method }\end{array}$ & $\begin{array}{c}\tau_{1}^{\text {total }} \\
{\left[\mathrm{N} / \mathrm{mm}^{2}\right]} \\
\text { obtained } \\
\text { by the } \\
\text { proposed } \\
\text { method }\end{array}$ & $\begin{array}{c}\tau_{2}^{\text {total }} \\
{\left[\mathrm{N} / \mathrm{mm}^{2}\right]} \\
\text { obtained } \\
\text { by the } \\
\text { proposed } \\
\text { method }\end{array}$ & $\begin{array}{c}\tau_{1}^{\text {total }} \\
{\left[\mathrm{N} / \mathrm{mm}^{2}\right]} \\
\text { obtained } \\
\text { by [5] }\end{array}$ & $\begin{array}{c}\tau_{2}^{\text {total }} \\
{\left[\mathrm{N} / \mathrm{mm}^{2}\right]} \\
\text { obtained } \\
\text { by [5] }\end{array}$ \\
\hline 3000 & 17.082 & 8.846 & 2.037 & 19.119 & 8.846 & 18.100 & 7.820 \\
\hline 2000 & 17.810 & 9.223 & 2.187 & 19.997 & 9.223 & 18.810 & 8.190 \\
\hline 1000 & 18.599 & 9.631 & 2.351 & 20.950 & 9.631 & 19.620 & 8.550 \\
\hline 0 & 19.457 & 10.076 & 2.531 & 21.988 & 10.076 & 20.630 & 9.000 \\
\hline-1000 & 20.394 & 10.561 & 2.727 & 23.121 & 10.561 & 21.530 & 9.430 \\
\hline-2000 & 21.422 & 11.093 & 2.944 & 24.366 & 11.093 & 22.620 & 10.010 \\
\hline-3000 & 22.554 & 11.680 & 3.184 & 25.738 & 11.680 & 23.830 & 10.550 \\
\hline
\end{tabular}

\subsection{Elastostatic analyses of a fork-fork supported beam with a rectangular hollow cross-section, subjected to an axial load and a uniformly distributed torsional moment}

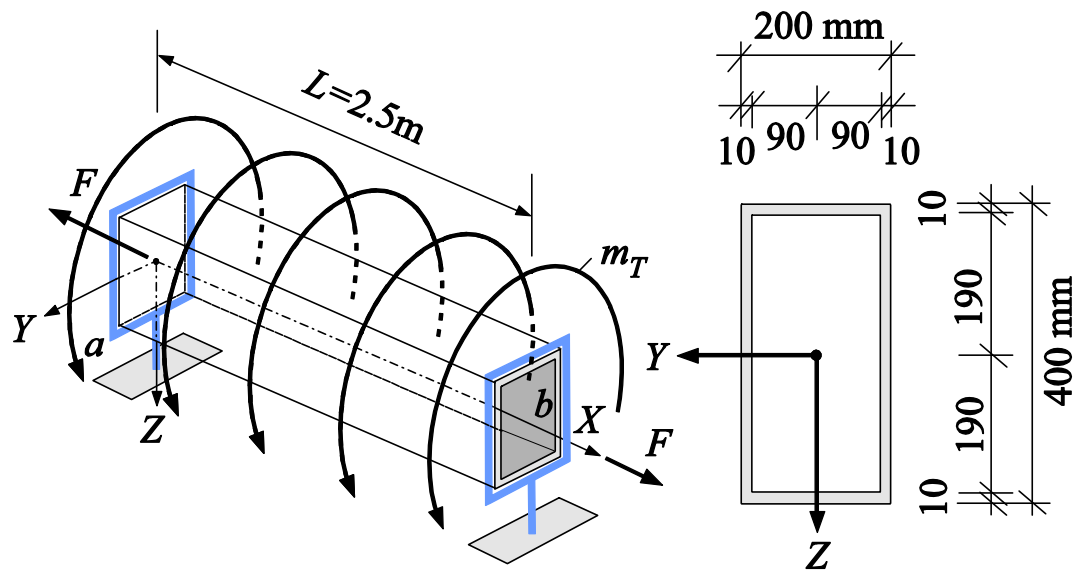

a)

b)

Fig. 13: Fork-fork supported beam with rectangular hollow cross-section: a) system, axial load, torsional moment, b) cross-section.

The length of the beam, $L$, is $2.5 \mathrm{~m}$. The material properties and the cross-sectional parameters are listed in Table 1 and Table 9, respectively. The elastostatic analyses are performed for the beam for the following axial force:

$$
N^{\mathrm{II}}(x)=N(x)=F=1500 \mathrm{kN} .
$$

The torsional moment is assumed to be constant:

$$
m_{T}(x)=200[\mathrm{kNm} / \mathrm{m}] .
$$

Table 9: Cross-sectional parameters [29]. 


\begin{tabular}{|c|c|c|}
\hline Cross-sectional area & $A=116 \cdot 10^{-4}$ & $\mathrm{~m}^{2}$ \\
\hline Shear area in the $y$ - direction & $A_{y}=25.26 \cdot 10^{-4}$ & $\mathrm{~m}^{2}$ \\
\hline Shear area in the $z$ - direction & $A_{z}=71.59 \cdot 10^{-4}$ & $\mathrm{~m}^{2}$ \\
\hline Second moment of area about the $y$-axis & $I_{y}=24358 \cdot 10^{-8}$ & $\mathrm{~m}^{4}$ \\
\hline Second moment of area about the $z$-axis & $I_{z}=8198 \cdot 10^{-8}$ & $\mathrm{~m}^{4}$ \\
\hline Polar moment of area & $I_{p}=I_{y}+I_{z}=32557 \cdot 10^{-8}$ & $\mathrm{~m}^{4}$ \\
\hline Radius of gyration & $i_{p}=16.75 \cdot 10^{-2}$ & $\mathrm{~m}$ \\
\hline
\end{tabular}

As regards the proposed method, only one finite element was used for the whole beam. The boundary conditions according to second-order torsional warping theory are given as follow:

$$
\begin{array}{ll}
\left.\psi(x)\right|_{x=0}=\psi_{a}=0, & \left.M_{\omega}(x)\right|_{x=0}=M_{\omega, a}=0, \\
\left.\psi(x)\right|_{x=L}=\psi_{b}=0, & \left.M_{\omega}(x)\right|_{x=L}=M_{\omega, b}=0 .
\end{array}
$$

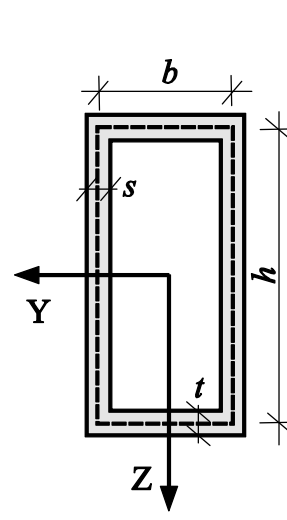

a)

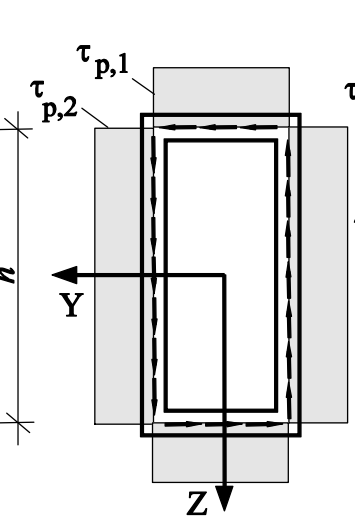

b)

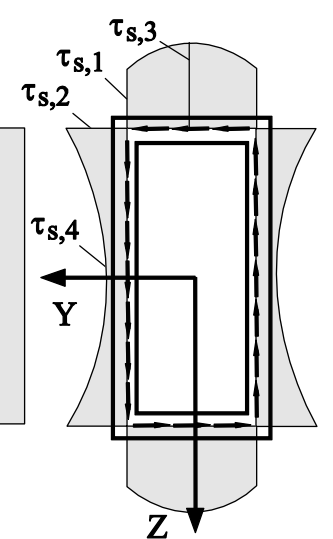

c)

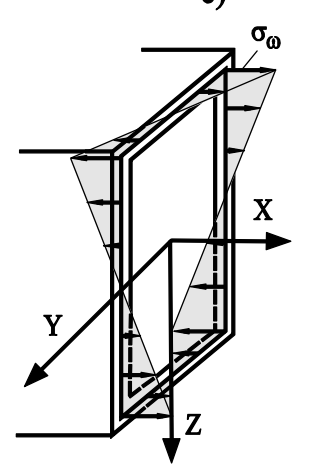

e)

Fig. 14: a) Cross-section, b) primary shear stress, c) secondary shear stress, d) axial stress due to axial forces e) axial stress due to warping

Table 10 contains the cross-sectional parameters, which are taken from [32]. 
Table 10: Cross-sectional parameters [32].

\begin{tabular}{|c|c|c|}
\hline Torsion constant & $I_{T}=18933.8 \cdot 10^{-8}$ & $\mathrm{~m}^{4}$ \\
\hline Secondary torsion constant & $I_{T S}=1953.6 \cdot 10^{-8}$ & $\mathrm{~m}^{4}$ \\
\hline Warping constant & $I_{\omega}=157782 \cdot 10^{-12}$ & $\mathrm{~m}^{6}$ \\
\hline Warping-ordinate at the corner points & $\left|\omega_{R}\right|=63.879 \cdot 10^{-2}$ & $\mathrm{~m}^{2}$ \\
\hline Radius of gyration & $i_{p}=16.75 \cdot 10^{-4}$ & $\mathrm{~m}$ \\
\hline
\end{tabular}

The equations (52)-(58) are taken from [32]:

$$
\begin{gathered}
A_{S}=s h, \quad A_{G}=t b, \quad A=2\left(A_{G}+A_{S}\right), \\
\alpha=\frac{h}{s}, \quad \beta=\frac{b}{t}, \quad \gamma=\alpha+\beta, \quad \omega_{R}=\frac{b h}{4} \frac{\alpha-\beta}{\gamma}, \\
I_{T}=\frac{2(h b)^{2}}{\gamma}, \quad I_{\omega}=\omega_{R}^{2} \frac{A}{3}, \quad I_{T s}=\frac{20 \gamma I_{\omega} A}{\frac{(A h b)^{2}}{A_{S} A_{G}}+\frac{\left(h^{2}-b^{2}\right)^{2}}{1.5}} \\
S_{0}=\frac{h^{2}-b^{2}}{6 \gamma} \omega_{R}, \quad S_{1}=S_{0}+A_{G} \frac{\omega_{R}}{4}, \quad S_{2}=S_{0}-A_{S} \frac{\omega_{R}}{4},
\end{gathered}
$$

The axial stresses due to the warping moment at the corner points are given as follows:

$$
\sigma_{\omega}= \pm \frac{M_{\omega}}{I_{\omega}} \omega_{R}
$$

The total axial stress is obtained as follows:

$$
\sigma_{\text {total }}=\sigma_{n} \pm \sigma_{\omega}, \text { where } \sigma_{n}=\frac{N}{A} .
$$

The shear stress resulting from the secondary moment is given as

$$
\tau_{s, 1}=\frac{M_{T s}}{t I_{\omega}} S_{0}, \quad \tau_{s, 2}=\frac{M_{T s}}{s I_{\omega}} S_{0}, \quad \tau_{s, 3}=\frac{M_{T s}}{t I_{\omega}} S_{1} \quad \tau_{s, 4}=\frac{M_{T s}}{s I_{\omega}} S_{2} .
$$

The shear stress resulting from the primary moment is given as

$$
\tau_{p, 1}=\frac{M_{T p} s b h}{I_{T}^{*}(h t+b s)}, \quad \tau_{p, 2}=\frac{M_{T p} t b h}{I_{T}^{*}(h t+b s)}, \text { with } I_{T}^{*}(x)=\frac{G I_{T}+N^{I I}(x) i_{p}^{2}}{G} .
$$


According to Fig. 14, the total shear stress is obtained as follows:

$$
\begin{aligned}
& \tau_{1}^{\text {total }}=\tau_{s, 1}+\tau_{p, 1}, \quad \tau_{3}^{\text {total }}=\tau_{s, 3}+\tau_{p, 1}, \\
& \tau_{2}^{\text {total }}=\tau_{s, 2}+\tau_{p, 2}, \quad \tau_{4}^{\text {total }}=\tau_{s, 4}+\tau_{p, 2} .
\end{aligned}
$$

Table 11 permits a comparison of the results for the total axial stress at midpoint $x=L / 2=1.25 \mathrm{~m}$, obtained by the proposed method with only one element, with corresponding results obtained by ABAQUS/CAE [5] 44156 Elements, Type: $\mathrm{C} 3 \mathrm{D} 8 \mathrm{R}$ for a fork-fork supported beam with a rectangular hollow cross-section, subjected to the axial force $N^{\mathrm{II}}=N=F=1500 \mathrm{kN}$ and to uniformly distributed torsional moments $m_{T}=200 \mathrm{kNm} / \mathrm{m}$.

Table 11: Total axial stress at the midpoint $x=L / 2=1.25 \mathrm{~m}$, obtained by the proposed method and by ABAQUS/CAE [5] 44156 Elements, Type: C3D8R.

\begin{tabular}{|c|c|c|c|c|c|}
\hline & $\begin{array}{c}M_{\omega} \\
{\left[\mathrm{kNm}^{2}\right]}\end{array}$ & $\begin{array}{c}\sigma_{n} \\
{\left[\mathrm{~N} / \mathrm{mm}^{2}\right]}\end{array}$ & $\begin{array}{c}\sigma_{\omega} \\
{\left[\mathrm{N} / \mathrm{mm}^{2}\right]}\end{array}$ & $\begin{array}{c}\min \sigma^{\text {total }} \\
{\left[\mathrm{N} / \mathrm{mm}^{2}\right]}\end{array}$ & $\begin{array}{c}\max \sigma^{\text {total }} \\
{\left[\mathrm{N} / \mathrm{mm}^{2}\right]}\end{array}$ \\
\hline $\begin{array}{c}\text { proposed } \\
\text { method }\end{array}$ & 0.4319 & 129.310 & 17.486 & 111.82 & 146.80 \\
\hline $\begin{array}{c}\text { obtained } \\
\text { by [5] }\end{array}$ & ------- & ------ & ----- & 111.65 & 146.02 \\
\hline
\end{tabular}

Table 12 permits a comparison of the results for the total shear stress at the starting point $x=0 \mathrm{~m}$, obtained by the proposed method and by ABAQUS/CAE [5] 44156 Elements, Type: C3D8R for a fork-fork supported beam with a rectangular hollow cross-section, subjected to an axial force $N^{\mathrm{II}}=N=F=1500 \mathrm{kN}$ and a uniformly distributed torsional moment $m_{T}=200 \mathrm{kNm} / \mathrm{m}$.

Table 12: Total shear stress at the starting point $x=0 \mathrm{~m}$, obtained by proposed method and by ABAQUS/CAE [5] 44156 Elements, Type: C3D8R.

\begin{tabular}{|c|c|c|c|c|c|}
\hline & $\begin{array}{c}\tau_{p, 1}=\tau_{p, 2} \\
{\left[\mathrm{~N} / \mathrm{mm}^{2}\right]}\end{array}$ & $\begin{array}{c}\tau_{s, 2} \\
{\left[\mathrm{~N} / \mathrm{mm}^{2}\right]}\end{array}$ & $\begin{array}{c}\tau_{s, 3} \\
{\left[\mathrm{~N} / \mathrm{mm}^{2}\right]}\end{array}$ & $\begin{array}{c}\tau_{2}^{\text {total }} \\
{\left[\mathrm{N} / \mathrm{mm}^{2}\right]}\end{array}$ & $\begin{array}{c}\tau_{3}^{\text {total }} \\
{\left[\mathrm{N} / \mathrm{mm}^{2}\right]}\end{array}$ \\
\hline $\begin{array}{c}\text { proposed } \\
\text { method }\end{array}$ & 166.775 & 3.832 & 9.293 & 170.15 & 175.61 \\
\hline $\begin{array}{c}\text { obtained by } \\
{[5]}\end{array}$ & ------- & ------ & ------ & 172.90 & 177.40 \\
\hline
\end{tabular}

The quality of the agreement of the results for the total shear stresses is very good.

\section{Summary and conclusions}


In this paper, the differential equation for the torsional deformation of a beam, subjected to variable axial forces, was formulated for Saint-Venant and non-uniform torsional deformations, including inertial line moments. The influence of the axial force on the torsional stiffness of the thin-walled beam was considered according to second-order torsional warping theory. For non-uniform torsion, the part of the bicurvature, caused by the bimoment, was taken into account as the warping degree of freedom, and the STMDE was also considered. A general semi-analytical solution of the differential equation was presented and the transfer matrix relation was established. Based on the relations of the transfer matrix method, a straight finite beam element with two nodes was derived. Omitting the external load, the relationship for the torsional free vibrations was obtained in the framework of the FEM. The numerical investigation involved torsional modal and elastostatic analysis of thin-walled beams with I cross-sections and rectangular hollow cross-sections. The obtained results were compared with the ones computed with the help of commercial FEM codes. The new finite element for non-uniform torsion of thinwalled beams has proved to be very effective and accurate. It was also shown that the tensile axial forces result in an increase of the eigenfrequencies, whereas compressive axial forces lead to their decrease. In structural analysis, the axial stresses, caused by the bimoment, exhibit a significant influence on the total axial stresses.

The main novelties of this paper are:

- (1) consideration of a variable axial force and of the STMDE in the differential equation for non-uniform torsion of thin-walled beams with open and closed crosssections according to the theory of second-order torsional warping;

- (2) the formulation of the transfer matrix method and its use for the development of a finite beam element for elastostatic and modal analysis of non-uniformly twisted beams according to second-order torsional warping theory.

\section{Appendices}

\subsection{Derivation of the transformation matrix $T$}

The first row of the transformation matrix $\boldsymbol{T}$ is given as follows:

$$
t_{11}=1, t_{12}=0, t_{13}=0, t_{14}=0, t_{15}=0,
$$

The second row of the transformation matrix $\boldsymbol{T}$ is obtained by inserting equation (6) into equation (9) and equation (10) into equation (8) and combining the results to

$$
\frac{G I_{T s}}{G I_{T}^{*}+G I_{T S}} \psi_{M}^{\prime}+\frac{1}{G I_{T}^{*}+G I_{T s}} M_{T}=0 .
$$

$t_{22}$ is the coefficient of $\psi_{M}^{\prime}$ and $t_{24}$ is the one of $M_{T}$. Thus,

$$
t_{21}=0, \quad t_{22}=\frac{G I_{T S}}{G I_{T}^{*}+G I_{T S}}, \quad t_{23}=0, \quad t_{24}=\frac{1}{G I_{T}^{*}+G I_{T S}}, \quad t_{25}=0 .
$$


The third row of the transformation matrix $\boldsymbol{T}$ follows from differentiation of equation (62) with respect to $x$ and consideration of equation (7):

$$
\begin{aligned}
& -\frac{\rho I_{p} \omega^{2}}{G I_{T S}+G I_{T}^{*}} \psi-\frac{G I_{T S} G I_{T}^{* \prime}}{\left(G I_{T S}+G I_{T}^{*}\right)^{2}} \psi_{M}^{\prime}-\frac{G I_{T S}}{E I_{\omega}\left(G I_{T S}+G I_{T}^{*}\right)} M_{\omega} \\
& -\frac{G I_{T}^{* \prime}}{\left(G I_{T s}+G I_{T}^{*}\right)^{2}} M_{T}-\frac{m_{T}}{G I_{T S}+G I_{T}^{*}}=0 .
\end{aligned}
$$

By analogy to (63),

$$
\begin{gathered}
t_{31}=-\frac{\rho I_{p} \omega^{2}}{G I_{T S}+G I_{T}^{*}}, \quad t_{32}=-\frac{G I_{T S} G I_{T}^{* \prime}}{\left(G I_{T S}+G I_{T}^{*}\right)^{2}}, \quad t_{33}=-\frac{G I_{T S}}{E I_{\omega}\left(G I_{T S}+G I_{T}^{*}\right)}, \\
t_{34}=-\frac{G I_{T}^{* \prime}}{\left(G I_{T S}+G I_{T}^{*}\right)^{2}}, \quad t_{35}=-\frac{m_{T}}{G I_{T s}+G I_{T}^{*}} .
\end{gathered}
$$

The fourth row of the transformation matrix $\boldsymbol{T}$ is obtained from differentiation of equation (64) and combination of the equations (7), (5), and (62):

$$
\begin{gathered}
t_{41}=\frac{2 \rho I_{p} \omega^{2} G I_{T}^{* \prime}}{\left(G I_{T s}+G I_{T}^{*}\right)^{2}}, t_{43}=\frac{2 G I_{T s} G I_{T}^{* \prime}}{E I_{\omega}\left(G I_{T s}+G I_{T}^{*}\right)^{2}}, \\
t_{42}=\frac{G I_{T s}}{\left(G I_{T s}+G I_{T}^{*}\right)^{2}}\left(\begin{array}{c}
\frac{\left(\left(E I_{\omega} \rho I_{p}+G I_{T s} \rho I_{\omega}\right) \omega^{2}+\left(\rho I_{\omega} \omega^{2}-G I_{T s}\right) G I_{T}^{*}\right)}{E I_{\omega}} \\
+\frac{2 G I_{T}^{* \prime 2}}{\left(G I_{T s}+G I_{T}^{*}\right)}-G I_{T}^{* \prime \prime}
\end{array}\right), \\
t_{44}=\frac{\left(E I_{\omega} \rho I_{p} \omega^{2}+G I_{T s}^{2}\right)\left(G I_{T s}+G I_{T}^{*}\right)}{E I_{\omega}}-2 G I_{T}^{* \prime 2}+\left(G I_{T s}+G I_{T}^{*}\right) G I_{T}^{* \prime \prime} \\
t_{45}=-\frac{G I_{T s}\left(G I_{T s}+G I_{T}^{*}\right) m_{\omega}}{E I_{\omega}\left(G I_{T s}+G I_{T}^{*}\right)^{2}}+\frac{2 G I_{T}^{* \prime} m_{T}}{\left(G I_{T s}+G I_{T}^{*}\right)^{2}}-\frac{\left(G I_{T s}+G I_{T}^{*}\right) m_{T}^{\prime}}{E I_{\omega}\left(G I_{T s}+G I_{T}^{*}\right)^{2}} .
\end{gathered}
$$

\subsection{Derivation of the element stiffness matrix $K$}

Based on the transfer matrix $\boldsymbol{F}_{x i}(x)$, specialized for $x=L$ by changing of rows and columns and of the signs according to Fig. 3 , the coefficients of the element stiffness matrix $\boldsymbol{K}$ are obtained as follows: 


$$
\begin{aligned}
& K_{11}=\frac{f_{1,3} f_{2,1}-f_{1,1} f_{2,3}}{-f_{1,4} f_{2,3}+f_{1,3} f_{2,4}}, \quad K_{12}=\frac{f_{1,3} f_{2,2}-f_{1,2} f_{2,3}}{-f_{1,4} f_{2,3}+f_{1,3} f_{2,4}}, \quad K_{13}=\frac{f_{2,3}}{-f_{1,4} f_{2,3}+f_{1,3} f_{2,4}}, \\
& K_{14}=\frac{f_{1,3}}{-f_{1,4} f_{2,3}+f_{1,3} f_{2,4}}, \quad K_{15}=-\frac{f_{1,5} f_{2,3}-f_{1,3} f_{2,5}}{-f_{1,4} f_{2,3}+f_{1,3} f_{2,4}}, \quad K_{21}=\frac{-f_{1,4} f_{2,1}+f_{1,1} f_{2,4}}{-f_{1,4} f_{2,3}+f_{1,3} f_{2,4}} \text {, } \\
& K_{22}=-\frac{-f_{1,4} f_{2,2}+f_{1,2} f_{2,4}}{-f_{1,4} f_{2,3}+f_{1,3} f_{2,4}}, \quad K_{23}=\frac{f_{2,4}}{-f_{1,4} f_{2,3}+f_{1,3} f_{2,4}}, \\
& K_{24}=-\frac{f_{1,4}}{-f_{1,4} f_{2,3}+f_{1,3} f_{2,4}}, K_{25}=-\frac{f_{1,5} f_{2,4}-f_{1,4} f_{2,5}}{f_{1,4} f_{2,3}-f_{1,3} f_{2,4}}, \\
& K_{31}=f_{1,4}-\frac{f_{1,1} f_{4,3}}{f_{1,3}}+\frac{-f_{1,1} f_{1,4} f_{2,3} f_{4,3}+f_{1,3}\left(f_{1,4} f_{2,1} f_{4,3}-f_{1,3} f_{2,1} f_{4,4}+f_{1,1} f_{2,3} f_{4,4}\right)}{-f_{1,4} f_{2,3}+f_{1,3} f_{2,4}} \\
& K_{32}=-f_{4,2}+\frac{f_{1,2} f_{4,3}}{f_{1,3}}+\frac{f_{1,3}\left(-f_{1,4} f_{2,2} f_{4,3}+f_{1,3} f_{2,2} f_{4,4}-f_{1,1} f_{2,3} f_{4,4}\right)+f_{1,2} f_{1,4} f_{2,3} f_{4,3}}{-f_{1,4} f_{2,3}+f_{1,3} f_{2,4}} \\
& K_{33}=\frac{f_{4,3}}{f_{1,3}}-\frac{f_{1,4} f_{2,3} f_{4,3}+f_{1,3} f_{2,3} f_{4,4}}{f_{1,3}\left(-f_{1,4} f_{2,3}+f_{1,3} f_{2,4}\right)}, \quad K_{34}=\frac{f_{1,4} f_{4,3}-f_{1,3} f_{4,4}}{-f_{1,4} f_{2,3}+f_{1,3} f_{2,4}}, \\
& K_{35}=f_{4,5}+\frac{f_{1,5} f_{2,4} f_{4,3}-f_{2,5} f_{1,4} f_{4,3}-f_{1,5} f_{2,3} f_{4,4}+f_{1,3} f_{2,5} f_{4,4}}{f_{1,4} f_{2,3}-f_{1,3} f_{2,4}}, \\
& K_{41}=f_{3,1}-\frac{f_{1,1} f_{3,3}}{f_{1,3}}+\frac{-f_{1,1} f_{1,4} f_{2,3} f_{3,3}+f_{1,3}\left(f_{1,4} f_{2,1} f_{3,3}-f_{1,3} f_{2,1} f_{3,4}+f_{1,1} f_{2,3} f_{3,4}\right)}{-f_{1,4} f_{2,3}+f_{1,3} f_{2,4}} \\
& K_{42}=-f_{3,2}+\frac{f_{1,2} f_{3,3}}{f_{1,3}}+\frac{f_{1,3}\left(-f_{1,4} f_{2,2} f_{3,3}+f_{1,3} f_{2,2} f_{3,4}-f_{1,2} f_{2,3} f_{3,4}\right)+f_{1,2} f_{1,4} f_{2,3} f_{3,3}}{-f_{1,4} f_{2,3}+f_{1,3} f_{2,4}} \\
& K_{43}=\frac{f_{3,3}}{f_{1,3}}+\frac{f_{1,4} f_{2,3} f_{3,3}-f_{1,3} f_{2,3} f_{3,4}}{f_{1,3}\left(-f_{1,4} f_{2,3}+f_{1,3} f_{2,4}\right)}, \quad K_{44}=\frac{f_{1,4} f_{3,3}-f_{1,3} f_{3,4}}{-f_{1,4} f_{2,3}+f_{1,3} f_{2,4}}, \\
& K_{45}=f_{3,5}+\frac{f_{1,5} f_{2,4} f_{3,3}-f_{2,5} f_{1,4} f_{3,3}-f_{1,5} f_{2,3} f_{3,4}+f_{1,3} f_{2,5} f_{3,4}}{f_{1,4} f_{2,3}-f_{1,3} f_{2,4}} .
\end{aligned}
$$

\section{Acknowledgements}

The research on which this paper is based was supported by the Slovak Grant Agencies VEGA No. 1/0453/15 and APVV-0246-12 and by the Austrian Science Fund (FWF) [M 2009-N32].

\section{References}

[1] M. Aminbaghai, J. Murin, J. Hrabovsky, H.A. Mang, Torsional warping eigenmodes including the effect of the secondary torsion-moment on the deformations, Eng. Struct. 106 (2016) 299 - 316. 
[2] I.C. Dikaros, E.J. Sapountzakis, A.K. Argyridi, Generalized warping effect in the dynamic analysis of beams of arbitrary cross section, Journal of Sound and Vibration 369 (2016), $119-146$.

[3] ANSYS Swanson Analysis System, Inc., 201 Johnson Road, Houston, PA $15342 / 1300$, USA.

[4] ADINA R \& D, Inc. Theory and Modelling Guide. Volume I: ADINA. 2013.

[5] ABAQUS/CAE, Version 6.10-1, Dassault Systemes Simulia Corp. Providence, RI, USA.

[6] J.S. Przemieniecki, Theory of matrix structural analysis. McGraw-Hill Book Co., 1968.

[7] K.J. Bathe, A. Chaudhary, On the displacement formulation of torsion of shafts with rectangular cross-sections, International Numerical Methods in Engineering 18 (1982) 1565 - 1568.

[8] E.J. Sapountzakis, V.J. Tsipiras, A.K. Argyridi, Torsional vibration analysis of bars including secondary torsional shear deformation-effect by the boundary element method, Journal of Sound and Vibration 355 (2015) 208 - 231.

[9] E.J. Sapountzakis, V.G. Mokos, Dynamic analysis of 3-D beam elements including warping and shear deformation-effects, Solids and Structures 43 (2016) $6707-6726$.

[10] E.J. Sapountzakis, V.J. Tsipiras, Nonlinear non-uniform torsional vibration, Non-linear Mechanics 329 (2010) 1853 - 1874.

[11] E.J. Sapountzakis, I.C. Dikaros, Non-linear flexural-torsional dynamic analysis of beams of arbitrary cross section by BEM, Non-linear Mechanics 46 (2011) $782-794$.

[12] S.A. Sina, H. Haddadpour, H.M. Navazi, Nonlinear free vibration of thin-walled beams in torsion, Acta Mechanica 233 (2012) 2135 - 2151.

[13] S.J. Lee, S.B. Park, Vibrations of Timoshenko beams with isogeometric approach, Applied Mathematical Modelling 37 (2013) 9174 - 9190.

[14] S. Stoykov, P. Ribeiro, Non-linear vibrations of beams with non-symmetrical cross sections, Non-linear Mechanics 55 (2013) 153 - 169.

[15] S.A. Sina, H. Haddadpour, Axial-torsional vibrations of rotated pretwisted thinwalled composite beams, Mechanical Sciences 80 (2014) 93 - 101.

[16] K.F. Ferradi, X. Cespedes, A new beam element with transversal and warping eigenmodes, Computers and Structures 131 (2014) $12-33$.

[17] K. Yoon, D.N. Kim, Geometrically nonlinear analysis of functionally graded 3D beams considering warping effects, Composite Structures 132 (2015) 1231 $-1247$.

[18] J. Murin, M. Aminbaghai, V. Kutis, V. Kralovic, V. Goga, H.A. Mang, A new 3D Timoshenko finite beam element including non-uniform torsion of open and closed cross sections, Engineering Structures 59 (2014) 153 - 60. 
[19] J. Murin, V. Goga, M. Aminbaghai, J. Hrabovsky, T. Sedlar, H.A. Mang, Measurement and modelling of torsional warping free vibrations of beams with rectangular hollow cross-sections, Engineering Structures 136 (2017) 68 - 76

[20] M. Arici, M.F. Granata, Unified theory for analysis of curved thin-walled girders with open and closed cross section through HSA method, Engineering Structures 113 (2016) 299 - 314.

[21] J. Freund, A. Karakoc, Warping displacement of Timoshenko beam model, Solid and Structures 92-93 (2016) 9- 16.

[22] S. Stoykov, E. Manoach, S. Margenov, An efficient 3D numerical beam model based on cross-sectional analysis and Ritz approximations, ZAMM 96 (2016) $791-812$.

[23] J. Xiaoliang, G.K. Narahara, Prediction of coupled torsional-axial vibrations of drilling tool with boundary conditions, Manufacturing Science and Technology 13 (2016) $24-36$.

[24] T. Mondal, S. Prakash, Nonlinear finite-element analysis of RC bridge columns under torsion with and without axial compression, Bridge Engineering 21 (2016) doi: 10.1061/(ASCE) BE.1943-5592.0000798.

[25] J. Fink, Besondere Stabilitätsprobleme im Stahlbau [in German; Specific stability issues in steel construction], Lecture Manuscript, Technical University of Vienna, 2005.

[26] H. Rubin, Wölbkrafttorsion von Durchlaufträgern mit konstantem Querschnitt unter Berücksichtigung sekundärer Schubverformung [in German; Torsional warping theory including the secondary torsion-moment deformation-effect for beams with constant cross-section], Stahlbau 74 (2005) 826-842.

[27] H. Rubin, Lösung linearer Differentialgleichungen beliebiger Ordnung mit Polynomkoeffizienten und Anwendung auf ein baustatisches Problem [in German; Solution concept for linear differential equations with non linear polynomial coefficients and application to engineering problems], Zeitschrift für Angewandte Mathematik und Mechanik 76-2 (1996) 105 - 117.

[28] Wolfram Mathematica 9.0.1.0, Wolfram Research 2013.

[29] DUENQ, Version 7.01, Dlubal.

[30] RSTAB 8.06, Ingenieur - Software Dlubal GmbH, Tiefenbach 2006.

[31] M. Schneider-Bürger, Stahlbau-Profile, Verlag Stahleisen GmbH, Düsseldorf 2001, volume 23.

[32] H. Rubin, Baustatik 2 [in German; Structural analysis 2]. Lecture Manuscript, Technical University of Vienna, 2005.

[33] RFEM 5.07, Ingenieur - Software Dlubal GmbH, Tiefenbach 2006. 